\title{
A human antibody against human endothelin receptor type $A$ that exhibits antitumor potency
}

\author{
Man-Seok Ju ${ }^{1,2,10}$, Hye-Mi Ahn ${ }^{3,10}$, Seong-Gu Han ${ }^{4,10}$, Sanghwan $\mathrm{Ko}^{1,2}$, Jung-Hyun Na ${ }^{5,6}$, Migyeong Jo ${ }^{1,7}$, Chung Su Lim ${ }^{8}$, \\ Byoung Joon $\mathrm{Ko}^{9}$, Yeon Gyu Yu${ }^{4}$, Won-Kyu Lee ${ }^{8}$, Youn-Jae Kim ${ }^{3 凶}$ and Sang Taek Jung $\mathbb{D}^{1,2,7 凶}$
}

(c) The Author(s) 2021

Endothelin receptor $A\left(E T_{A}\right)$, a class A G-protein-coupled receptor (GPCR), is involved in the progression and metastasis of colorectal, breast, lung, ovarian, and prostate cancer. We overexpressed and purified human endothelin receptor type $A$ in Escherichia coli and reconstituted it with lipid and membrane scaffold proteins to prepare an $\mathrm{ET}_{\mathrm{A}}$ nanodisc as a functional antigen with a structure similar to that of native GPCR. By screening a human naive immune single-chain variable fragment phage library constructed inhouse, we successfully isolated a human anti-ET $T_{A}$ antibody (AG8) exhibiting high specificity for $\mathrm{ET}_{\mathrm{A}}$ in the $\beta$-arrestin Tango assay and effective inhibitory activity against the ET-1-induced signaling cascade via $\mathrm{ET}_{\mathrm{A}}$ using either a $\mathrm{CHO}-\mathrm{K} 1$ cell line stably expressing human $\mathrm{ET}_{\mathrm{A}}$ or HT-29 colorectal cancer cells, in which AG8 exhibited $\mathrm{IC}_{50}$ values of 56 and $51 \mathrm{nM}$, respectively. In addition, AG8 treatment repressed the transcription of inhibin $\beta A$ and reduced the $\mathrm{ET}_{A}$-induced phosphorylation of protein kinase $B$ and extracellular regulated kinase. Furthermore, tumor growth was effectively inhibited by AG8 in a colorectal cancer mouse xenograft model. The human anti-ET $\mathrm{A}_{\mathrm{A}}$ antibody isolated in this study could be used as a potential therapeutic for cancers, including colorectal cancer.

Experimental \& Molecular Medicine (2021) 53:1437-1448; https://doi.org/10.1038/s12276-021-00678-9

\section{INTRODUCTION}

G-protein-coupled receptors (GPCRs), the largest superfamily of membrane receptors in the human genome, transduce extracellular signals to the intracellular space through binding of their cognate ligands. Intracellular signaling events triggered by conformational changes in GPCRs and interactions with intracellular proteins regulate numerous cellular functions, such as growth, motility, and differentiation ${ }^{1,2}$. Because of the critical role of GPCRs in numerous biological functions, they are involved in the progression and prognosis of a variety of diseases and are the targets of $\sim 35 \%$ of all commercialized drugs ${ }^{3,4}$.

Endothelin receptor type $A\left(E T_{A}\right)$ is a class $A$ GPCR that belongs to the endothelin receptor family. It regulates blood vessel constriction, cell growth, and differentiation through several downstream signaling pathways activated by the binding of ligands such as ET-1, ET-2, and ET-3 $3^{5,6}$. ET $\mathrm{A}_{\mathrm{A}}$, which undergoes a conformational change due to ligand binding, is involved in a variety of downstream signaling pathways through its interaction with $G$-protein alpha subunits $\left(G_{a s}, G_{a q / 11}\right.$, and $\left.G_{a i}\right)$ in the intracellular space ${ }^{7-9} . G_{\text {as }}$ and $G_{\text {ai }}$ control cell growth and motility in a manner dependent on the concentration of intracellular cyclic adenosine monophosphate (cAMP) produced by adenylyl cyclase, and $\mathrm{G}_{\mathrm{aq} / 11}$ regulates the intracellular $\mathrm{Ca}^{2+}$ concentration and cell proliferation through protein kinase $C(P K C)$ and activation of phospholipase $C \beta$ (PLC $\beta$ ). Therefore, $E_{A}$ expression is closely related to the survival rates of patients with several types of cancers $^{10-12}$, and endothelin receptor antagonists, including zibotentan, atrasentan, bosentan, macitentan, and ambrisentan, have been developed as drugs for treating cancer by inhibiting downstream $\mathrm{ET}_{\mathrm{A}}$ signaling ${ }^{13}$. Currently, $\mathrm{ET}_{\mathrm{A}}$ antagonists are being evaluated for their antitumor efficacy in a variety of preclinical and clinical trials for cancers such as melanoma, glioblastoma, prostate cancer, lung cancer, and colorectal cancer, which are closely related to the expression and activity of $\mathrm{ET}_{\mathrm{A}}{ }^{14}$. However, all $\mathrm{ET}_{\mathrm{A}}$ antagonists that have been evaluated for antitumor efficacy are small-molecule drugs.

Compared to small-molecule drugs, therapeutic antibodies have key advantages. First, they have extraordinarily high affinity and specificity for a target antigen, resulting in enhanced efficacy and reduced side effects. Second, they possess excellent Fc-mediated effector functions for clearance of target cells such as tumor cells. Third, they have prolonged circulating serum half-lives through $\mathrm{pH}$-dependent binding of FCRn to the IgG Fc region ${ }^{15,16}$. However, developing therapeutic antibodies against GPCR targets is challenging because of the low expression levels of GPCR antigens on native cell membranes or in heterologous hosts, the difficulty

\footnotetext{
${ }^{1}$ Department of Biomedical Sciences, Graduate School, Korea University, Seoul 02841, Republic of Korea. ${ }^{2}$ Institute of Human Genetics, Korea University College of Medicine, Seoul 02841, Republic of Korea. ${ }^{3}$ Division of Translational Science, Research Institute, National Cancer Center, Goyang, Gyeonggi-do 10408, Republic of Korea. ${ }^{4}$ Biopharmaceutical Chemistry Major, School of Applied Chemistry, Kookmin University, Seoul 02707, Republic of Korea. ${ }^{5}$ Department of Pharmaceutical Engineering, Sangji University, Wonju-si, Gangwon-do 26339, Republic of Korea. ${ }^{6}$ Research Institute of Korean Medicine, Sangji University, Wonju-si, Gangwon-do 26339 , Republic of Korea. ${ }^{7}$ BK21 Graduate Program, Department of Biomedical Sciences, Korea University College of Medicine, Seoul 02841, Republic of Korea. ${ }^{8}$ New Drug Development Center, Osong Medical Innovation Foundation, Cheongju, Chungcheongbuk-do 28160, Republic of Korea. ${ }^{9}$ School of Biopharmaceutical and Medical Sciences, Sungshin Women's University, Seoul 02844, Republic of Korea. ${ }^{10}$ These authors contributed equally: Man-Seok Ju, Hye-Mi Ahn, Seong-Gu Han. ${ }^{凶}$ email: gre7@kbiohealth.kr; yjkim@ncc.re.kr; sjung@korea.ac.kr
} 
of preparing a functional form of a GPCR antigen with a conformation similar to that of the complex seven transmembrane a-helical structure of native GPCRs, and the limited exposure of extracellular regions of GPCRs as a target for antibodies ${ }^{17,18}$. Due to these hurdles in developing anti-GPCR antibodies, only two therapeutic antibodies against GPCR antigens-erenumab (Aimovig $^{\circ}$ ) and mogamulizumab (Poteligeo ${ }^{\oplus}$ ), targeting the calcitonin gene-related peptide receptor and chemokine receptor 4, respectively-have been approved by the US FDA, in contrast to the clinical and marketing successes of a number of therapeutic antibodies targeting other types of antigens ${ }^{17}$.

In this study, we report the successful isolation of a human antibody antagonizing the functions of $\mathrm{ET}_{\mathrm{A}}$ and the evaluation of its antitumor activity. $\mathrm{ET}_{\mathrm{A}}$ nanodiscs were prepared by overexpressing $\mathrm{ET}_{\mathrm{A}}$ in $E$. coli and reconstituting the detergentsolubilized form with lipids and membrane scaffold proteins (MSPs). Screening of an in-house-constructed human antibody phage display library against $\mathrm{ET}_{\mathrm{A}}$ nanodiscs enabled us to isolate an antibody that binds specifically to $\mathrm{ET}_{\mathrm{A}}$. The resulting human antibody regulating the downstream signaling of human $\mathrm{ET}_{\mathrm{A}}$ showed potent antitumor effects in both in vitro tests and an in vivo xenograft mouse model. This study demonstrates that this antibody targeting human $\mathrm{ET}_{\mathrm{A}}$ could be used to elucidate the functions of endothelin receptors and could be developed as a potential therapeutic agent for cancer.

\section{MATERIALS AND METHODS \\ Reagents}

All oligonucleotide primers and plasmids used in this study are described in Supplementary Tables 1 and 2. Restriction enzymes, Phusion HighFidelity DNA polymerase, and T4 DNA ligase were purchased from New England Biolabs (Ipswich, MA, USA). Oligonucleotide primers and VCSM13 helper phage stock were obtained from Integrated DNA Technologies (Coralville, IA, USA) and Agilent Technologies (Santa Clara, CA, USA), respectively. 1-Palmitoyl-2-oleoylphosphatidylcholine (POPC), an anti-M13 antibody conjugated to horseradish peroxidase (HRP), and 1-Step ${ }^{T M}$ Ultra 3,3',5,5'-tetramethylbenzidine (TMB) substrates were purchased from Avanti Polar Lipids (Alabaster, AL, USA), Bethyl Laboratories (Montgomery, TX, USA), and Thermo Fisher Scientific (Waltham, MA, USA), respectively. All other chemicals and reagents were purchased from Sigma-Aldrich (St. Louis, MO, USA) unless stated otherwise.

\section{Construction of plasmids}

The mouse $\mathrm{ET}_{A}$ ( $m E T_{A}$ ) gene (NCBI Gene ID: 13617) was synthesized by GenScript (Piscataway, NJ, USA). The pP9-mET by Gibson assembly ${ }^{19}$ of the $\mathrm{mET}_{\mathrm{A}}$ DNA fragments amplified by polymerase chain reaction (PCR) using primers (MSJ\#01 and MSJ\#02) and the pP9 plasmid ${ }^{20}$ digested with the Smal restriction enzyme. The gene encoding membrane scaffold protein (MSP-1), derived from the apolipoprotein A-I gene (NCBI Gene ID: 335), was assembled by PCR using primers (MSJ\#03-MSJ\#08) and was subcloned into pET28a(+) (Novagen, Burlington, MA, USA) at the Ndel/BamHI restriction endonuclease sites to generate $\mathrm{pET} 28-\mathrm{MSP}-1$. To construct plasmids encoding the heavy and light chains of full-length IgG for AG8, each VH and VL gene was PCR amplified using a phagemid ( $p E L 3 X-A G 8$ ) isolated from the phage library screen and the primer pairs MSJ\#42/MSJ\#44 for VH and MSJ\#46/MSJ\#48 for VL. Then, the DNA fragments encoding the IgG constant region ( $\mathrm{CH} 1-$ $\mathrm{CH} 2-\mathrm{CH} 3$ ) of trastuzumab, which were prepared by PCR amplification using a primer pair (MSJ\#43/MSJ\#45) and a template (pMAZ-lgH-GlycoT) ${ }^{21}$, were assembled with the VH DNA fragments using a primer pair (MSJ\#42/ MSJ\#45). A primer pair (MSJ\#46/MSJ\#49) was used to assemble the DNA fragments for the VL gene, and the human $C_{k}$ DNA fragments were amplified using primers (MSJ\#47/MSJ\#49) and a template (pMAZ-IgLGlycoT) ${ }^{21}$. pMAZ-AG8H and pMAZ-AG8L were constructed by ligation of the resulting heavy and light-chain DNA of AG8 IgG, respectively, into the pMAZ-IgL-GlycoT plasmid at the BssHII and Xbal sites.

\section{Expression and purification of human $\mathrm{ET}_{\mathrm{A}}$, mouse $_{\mathrm{ET}} \mathrm{A}$, and membrane scaffold protein-1}

Human $\mathrm{ET}_{\mathrm{A}}\left(\mathrm{hET} \mathrm{T}_{\mathrm{A}}\right)$, mouse $\mathrm{ET}_{\mathrm{A}}\left(\mathrm{mET}_{\mathrm{A}}\right)$, and membrane scaffold protein-1 (MSP-1) proteins were expressed and purified as described in the literature ${ }^{20,22}$. E. coli BL21(DE3) harboring pP9-hET ${ }^{20}$ or $\mathrm{pP} 9-\mathrm{mET}_{\mathrm{A}}$ (for pP9-derived plasmids), or pET28a-MSP-1 (for pET28a-derived plasmids) was inoculated in Luria-Bertani (LB) medium supplemented with $100 \mu \mathrm{g} / \mathrm{ml}$ ampicillin (Millipore Sigma, Burlington, MA, USA) and $50 \mu \mathrm{g} / \mathrm{ml}$ kanamycin (Millipore Sigma, Burlington, MA, USA) and cultivated for $16 \mathrm{~h}$ at $37^{\circ} \mathrm{C}$ and $250 \mathrm{rpm}$. Then, 100 -fold dilutions of overnight-grown cells were inoculated in LB medium supplemented as needed with the same antibiotics and incubated at $37^{\circ} \mathrm{C}$ until the absorbance of the culture broth at $600 \mathrm{~nm}$ $\left(\mathrm{OD}_{600}\right)$ reached 0.6 . After the addition of isopropyl- $\beta$ - $D$-thiogalactopyranoside (IPTG) $\left(0.5 \mathrm{mM}\right.$ for $\mathrm{hET}_{\mathrm{A}}$ and $\mathrm{mET}_{\mathrm{A}}, 1 \mathrm{mM}$ for MSP-1) and incubation under specific culture conditions $\left(25^{\circ} \mathrm{C}\right.$ for $16 \mathrm{~h}$ for $\mathrm{hET}_{\mathrm{A}}$ and $\mathrm{mET}_{\mathrm{A}}, 30^{\circ} \mathrm{C}$ for $4 \mathrm{~h}$ for MSP-1) to induce protein expression, cells were harvested by centrifugation at $8000 \times g$ and disrupted using a microfluidizer (Microfluidics, Westwood, MA, USA). To prepare endothelin receptors ( $\mathrm{hET}_{\mathrm{A}}$ and $\left.m E T_{A}\right)$, the resulting lysates were centrifuged at $12,000 \times g$ for $20 \mathrm{~min}$, and the supernatants were ultracentrifuged at $100,000 \times g$ for $1.5 \mathrm{~h}$ to recover the membrane fractions from the pellets. After the membrane fractions were dissolved in $0.5 \%$ sarkosyl and centrifuged at $30,000 \times \mathrm{g}$ for $30 \mathrm{~min}$ to remove insoluble aggregates, the recovered supernatants were bound to Ni-NTA agarose (Qiagen, Germantown, MD, USA) equilibrated with Buffer A $(25 \mathrm{mM}$ Tris- $\mathrm{HCl}$ and $1 \mathrm{mM}$ phenylmethylsulfonylfluoride $(\mathrm{pH}$ 7.8)). After the resin was washed with 20 column volumes (CV) of Buffer A supplemented with $20 \mathrm{mM}$ imidazole, the resin-bound proteins were eluted using $5 \mathrm{CV}$ of Buffer A supplemented with $300 \mathrm{mM}$ imidazole. Then, the eluents were loaded onto a PD-10 desalting column (Cytiva, Marlborough, MA, USA) to remove excess imidazole, and the buffer was exchanged with $25 \mathrm{mM}$ Tris- $\mathrm{HCl}(\mathrm{pH}$ 7.8) containing $10 \%$ glycerol. The purified endothelin receptors $\left(\mathrm{hET}_{\mathrm{A}}\right.$ and $\mathrm{mET}_{\mathrm{A}}$ ) were stored at $-80^{\circ} \mathrm{C}$ before use. To prepare MSP-1 proteins, cell lysates were centrifuged at $12,000 \times g$, and the resulting supernatants were loaded onto a Ni-NTA column equilibrated with $10 \mathrm{ml}$ of $50 \mathrm{mM}$ Tris-Cl and $1 \%$ Triton X-100 (pH 7.4). After adding $10 \mathrm{ml}$ of $50 \mathrm{mM}$ Tris-Cl and $50 \mathrm{mM}$ imidazole (pH 7.4) for washing and $10 \mathrm{ml}$ of $50 \mathrm{mM}$ Tris-Cl and $300 \mathrm{mM}$ imidazole (pH 7.4) for elution, the eluent buffer was exchanged with $1 \times$ phosphate-buffered saline (PBS, pH 7.4) containing $10 \%$ glycerol using a PD-10 desalting column.

\section{Preparation of reconstituted $\mathbf{h E T}_{\mathbf{A}}$ nanodiscs}

Purified $\mathrm{hET}_{\mathrm{A}}$ and MSP-1 were mixed with POPC dissolved in $100 \mathrm{mM}$ sodium cholate at a $\mathrm{hET}_{\mathrm{A}}: \mathrm{MSP}-1: \mathrm{POPC}$ molar ratio of 1:30:60. After the addition of $200 \mathrm{mg} / \mathrm{ml}$ Bio-Beads ${ }^{\mathrm{TM}} \mathrm{SM}-2$ (Bio-Rad, Hercules, CA, USA), the resuspended solution was incubated at $4{ }^{\circ} \mathrm{C}$ for $16 \mathrm{~h}$ with mixing by rotation at $100 \mathrm{rpm}$ and centrifuged at $12,000 \times \mathrm{g}$ for $5 \mathrm{~min}$ to remove detergents. Then, the supernatants were dialyzed in $1 \times$ PBS $(\mathrm{pH} 7.4)$ and concentrated using Amicon Ultra ${ }^{\circledR} 4$ spin columns (Merck Millipore; $30 \mathrm{kDa}$ cutoff). The concentrated supernatants were loaded onto a Superdex 200 gel filtration chromatography column (Cytiva, Marlborough, MA, USA) for development in $35 \mathrm{ml}$ of $1 \times$ PBS (pH 7.4), and the fractions showing both $\mathrm{hET}_{\mathrm{A}}$ and MSP-1 protein bands in sodium dodecyl sulfate-polyacrylamide gel electrophoresis (SDS-PAGE) analysis were recovered.

\section{Construction of a human naive immune scFv library}

$\mathrm{VH}$ and $\mathrm{VL}$ genes of human immunoglobulins, which were prepared from peripheral blood mononuclear cells (PBMCs) of anonymous donors as described in the literature ${ }^{23}$, were PCR amplified using $200 \mu \mathrm{M}$ dNTPs, $1 \mu \mathrm{M}$ mixed oligonucleotides (MSJ\#07-MSJ\#16 for VH and MSJ\#17-MSJ\#37 for VL), 2.5 units of Phusion High-Fidelity DNA polymerase, and $100 \mathrm{ng}$ of CDNA as a template. Then, the VH and VL genes were assembled by PCR with two primers (MSJ\#38/MSJ\#39) to connect the resulting VH and VL genes with a flexible glycine-serine linker (GGGSSGGGGSGGGGSGGGGS), and the resulting $P C R$ products encoding the single-chain variable fragments (scFvs) were digested with Sfil and ligated into the pEL3X phagemid, which is a derivative of $\mathrm{pComb3X}^{24}$ with modified Sfil sequences (GGCCCAGCCGGCC/GGCCTCGGGGGCC). Then, the ligation products were transformed into E. coli ER2738 ( $\mathrm{F}^{\prime} \mathrm{proA}^{+} B^{+}$lacl $^{q} \Delta$ (lacZ) M15 zzf::Tn10(Tet $\left.{ }^{\mathrm{R}}\right) /$ fhuA2 glnV $\Delta$ (lac-proAB) thi-1 $\Delta$ (hsdS-mcrB)5) to generate the human naive scFv antibody library. 


\section{Preparation of phage particles from the scFv library}

E. coli ER2738 cells harboring naïve immune scFv library plasmids were inoculated and grown for $1 \mathrm{~h}$ in $10 \mathrm{ml}$ of Super Broth (SB) medium (Becton Dickinson Diagnostic Systems, Difco ${ }^{\mathrm{TM}}$, USA) supplemented with $100 \mu \mathrm{g} / \mathrm{ml}$ carbenicillin. The culture broth was diluted 1:100 in 1L of SB medium containing the same antibiotic and incubated at $37{ }^{\circ} \mathrm{C}$ with shaking at $250 \mathrm{rpm}$ until the absorbance of the culture broth at $600 \mathrm{~nm}$ reached $0.8-1.0$. Then, $1 \mathrm{ml}$ of VCSM13 helper phage $\left(1 \times 10^{12} \mathrm{pfu}\right)$ and $70 \mu \mathrm{g} / \mathrm{ml}$ kanamycin were added, and the infected cells were incubated for $16 \mathrm{~h}$ at $37^{\circ} \mathrm{C}$ with shaking at $250 \mathrm{rpm}$ to induce the production of scFv-displaying phage particles. The culture broth was centrifuged at $10,000 \times \mathrm{g}$, and the supernatants were mixed with polyethylene glycol (PEG)/NaCl solution containing 4\% (w/v) PEG 8000 and $3 \%(\mathrm{w} / \mathrm{v}) \mathrm{NaCl}$. The pellets were resuspended in $1 \times$ PBS and $3 \%$ bovine serum albumin $(\mathrm{pH} 7.4)$, and the recovered phage particles were stored at $4{ }^{\circ} \mathrm{C}$ prior to use.

\section{Library panning and screening}

In total, $50 \mu \mathrm{l}$ of $4 \mu \mathrm{g} / \mathrm{ml} \mathrm{G}_{\text {ai3 }}$ protein purified as described previously ${ }^{25}$ was coated onto a 96-well plate (Corning, Corning, NY, USA) at $4{ }^{\circ} \mathrm{C}$ for $16 \mathrm{~h}$. After extensive washing of the wells, $50 \mu \mathrm{l}$ of $\mathrm{hET}_{\mathrm{A}}$ reconstituted nanodiscs $(4 \mu \mathrm{g} / \mathrm{ml})$ was added, and the plate was incubated at room temperature for $2 \mathrm{~h}$. Before loading the library phage particles into the wells of the plate immobilized with $\mathrm{hET}_{\mathrm{A}}$ nanodiscs, a negative selection procedure was conducted. The library phage particles were incubated in wells immobilized with empty nanodiscs consisting of only MSP-1 and a lipid that did not contain $\mathrm{hET}_{\mathrm{A}}$. Next, $50 \mu \mathrm{l}$ of the resulting supernatants were added to the wells preimmobilized with $\mathrm{hET}_{\mathrm{A}}$ nanodiscs. After the plate was washed with $1 \times$ PBS (pH 7.4), bound phage particles were eluted in $100 \mu \mathrm{l}$ of glycine-HCl buffer ( $\mathrm{pH} 2.2)$ and neutralized by the addition of $20 \mu \mathrm{l}$ of $2 \mathrm{M}$ Tris ( $\mathrm{pH}$ 8.0). Then, $120 \mu \mathrm{l}$ of the resulting neutralized, recovered phages and $1 \mathrm{ml}$ of VCSM13 helper phage particles were added to infect $E$. coli ER2738, and the amplified phages were used for the next round of biopanning. The number of washing cycles was increased in each subsequent round of biopanning to enrich high-affinity binders. After five rounds of biopanning, E. coli ER2738 cells were infected with eluted phages, and 400 individual clones were cultured in $1 \mathrm{ml}$ of SB medium at $37^{\circ} \mathrm{C}$ with shaking at $250 \mathrm{rpm}$ until the $\mathrm{OD}_{600}$ reached 0.6 . Then, $50 \mu \mathrm{l}$ of VCSM13 helper phages and $70 \mu \mathrm{g} / \mathrm{ml}$ kanamycin were added to the infected E. coli ER2738 cells. After overnight cultivation, the supernatant was used for phage enzyme-linked immunosorbent assay (ELISA).

\section{Phage ELISA}

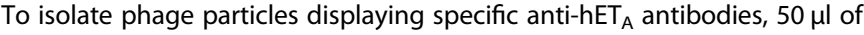
$4 \mu \mathrm{g} / \mathrm{ml}$ purified human $\mathrm{G}_{\text {ai3 }}$ protein diluted in $0.05 \mathrm{M} \mathrm{Na}_{2} \mathrm{CO}_{3}(\mathrm{pH}$ 9.6) was added to each well of a 96-well plate (Corning, Corning, NY, USA) and incubated at $4{ }^{\circ} \mathrm{C}$ for $16 \mathrm{~h}$. After blocking with $150 \mu \mathrm{l}$ of $4 \%$ skim milk in $1 \times$ PBS (pH 7.4) and washing four times with $150 \mu \mathrm{l}$ of PBS (pH 7.4) containing $0.02 \% \mathrm{n}$-dodecyl- $\beta$-D-maltoside (DDM), $50 \mu \mathrm{l}$ of $5 \mu \mathrm{g} / \mathrm{ml} \mathrm{hET}$ A reconstituted nanodiscs was added to each well of the plate. Then, the plate was incubated at $25^{\circ} \mathrm{C}$ for $1 \mathrm{~h}$, washed with $150 \mu \mathrm{l}$ of $1 \times$ PBS (pH 7.4) containing $0.02 \%$ DDM, and treated with $50 \mu \mathrm{l}$ of rescued phage particles displaying scFvs. After incubating at $25^{\circ} \mathrm{C}$ for $1 \mathrm{~h}$ and washing four times, $50 \mu \mathrm{l}$ of anti-M13-HRP conjugates diluted 4000 -fold in $1 \times$ PBS (pH 7.4) containing $0.02 \%$ DDM was added to the plate. After incubation for $1 \mathrm{~h}$ at $25^{\circ} \mathrm{C}$ and four washes in $150 \mu \mathrm{l}$ of $1 \times$ PBS containing $0.02 \%$ DDM (pH 7.4), $50 \mu \mathrm{l}$ of $1-$ Step $^{\mathrm{TM}}$ Ultra TMB was added to each well, and the plate was incubated for $20 \mathrm{~min}$ to develop the signal. After quenching the signal by the addition of $50 \mu \mathrm{l}$ of $4 \mathrm{~N} \mathrm{H}_{2} \mathrm{SO}_{4}$, the ELISA-binding signal was detected by measuring the absorbance at $450 \mathrm{~nm}$ in an Epoch plate reader (BioTek, Winooski, VT, USA).

\section{Luciferase assay}

A luciferase assay was performed using a dual-luciferase reporter assay system (Promega, Madison, WA, USA) according to the manufacturer's instructions. Poly-L-lysine was coated onto 96-well plates (Corning, Corning, NY, USA) by incubation at $37^{\circ} \mathrm{C}$ for $1 \mathrm{~h}$, and cells were then seeded at a density of $5 \times 10^{3}$ cells/well. The luciferase reporter plasmids were cotransfected with the control plasmid encoding Renilla luciferase into the cells in the plate, and AG8 phage supernatants were added after $24 \mathrm{~h}$. Then, a mixture of dye reagent was added after $48 \mathrm{~h}$, and luciferase activity was measured using a VICTOR Light luminometer (PerkinElmer, Inc., Waltham, MA, USA). The transfection efficiency was evaluated by normalization to Renilla luciferase activity as a control.

\section{Mammalian cell culture}

$\mathrm{CHO}-\mathrm{K} 1$ cells expressing human $\mathrm{ET}_{\mathrm{A}}$ were maintained as monolayer cultures on $100-\mathrm{mm}$ cell culture dishes in Ham's F12 medium supplemented with $10 \%$ fetal bovine serum (FBS) and $1 \times$ antibiotic-antimycotic solution at $37^{\circ} \mathrm{C}$ in a humidified atmosphere containing $5 \% \mathrm{CO}_{2}$. The established human colorectal cancer cell lines HT-29 and HCT-116 were purchased from the Korean Cell Line Bank (Seoul, Korea) and maintained in HyClone RPMI-1640 medium (Cytiva, Marlborough, MA, USA) supplemented with 10\% HyClone FBS (Cytiva, Marlborough, MA, USA), 1\% penicillinstreptomycin, and $1 \%$ sodium pyruvate at $37^{\circ} \mathrm{C}$ in a humidified atmosphere of $5 \% \mathrm{CO}_{2}$.

\section{Expression and purification of AG8 IgG}

The pMAZ-AG8H and pMAZ-AG8L plasmids, which encode the heavy and light chains of AG8 IgG, respectively, were constructed using an eCube Plasmid DNA Mini Kit (PhileKorea, Seoul, Korea) and transfected into Expi293 cells using polyethyleneimine, as described in the literature ${ }^{26}$ After resuspension of the cells in $300 \mathrm{ml}$ of GIBCO FreeStyle ${ }^{\mathrm{TM}}$ medium (Thermo Fisher Scientific, Waltham, MA, USA), incubation at $37^{\circ} \mathrm{C}$ with shaking at $125 \mathrm{rpm}$ under $8 \% \mathrm{CO}_{2}$ for 6 days, and centrifugation at $4000 \times g$, the supernatants were mixed with $40 \mathrm{ml}$ of $25 \times \mathrm{PBS}(\mathrm{pH} 7.4$ ) and $1 \mathrm{ml}$ of a slurry of Protein A agarose resin (GenScript, Piscataway, NJ, USA). The resuspension was incubated at $4^{\circ} \mathrm{C}$ for $16 \mathrm{~h}$ and passed through a polypropylene column (Thermo Fisher Scientific, Waltham, MA, USA) to recover the resin. Next, $100 \mathrm{ml}$ of $1 \times \mathrm{PBS}(\mathrm{pH} 7.4)$ was added to the column to wash the resin, and $3 \mathrm{ml}$ of $100 \mathrm{mM}$ glycine- $\mathrm{HCl}$ buffer $(\mathrm{pH} 2.5)$ was loaded onto the column for elution. The eluents were immediately neutralized by the addition of $1 \mathrm{ml}$ of Tris- $\mathrm{Cl}(\mathrm{pH}$ 8.0). After buffer exchange with $1 \times$ PBS ( $\mathrm{pH}$ 7.4) using Amicon Ultra 4 spin columns (Merck Millipore; $3-k D a$ cutoff), the concentration and purity of AG8 $\lg G$ were analyzed by measuring the absorbance at $280 \mathrm{~nm}$ and by $4-15 \%$ SDS-PAGE.

\section{Physicochemical analysis of AG8 IgG}

Antibody aggregation was measured with a Waters Alliance 2695 system (Milford, MA, USA) and a Waters BioSuite high-resolution size-exclusion chromatography (SEC) column $(7.5 \mathrm{~mm} \times 300 \mathrm{~mm}, 10-\mu \mathrm{m}$ particle size). Samples $(10 \mu \mathrm{l}, 1 \mathrm{mg} / \mathrm{ml})$ were injected, and separation was conducted using isocratic elution with $1 \times \mathrm{PBS}(\mathrm{pH} 7.4)$ at a flow rate of $1 \mathrm{ml} / \mathrm{min}$. The purity was analyzed with reversed-phase high-performance liquid chromatography (RP-HPLC) using an Agilent 1260 Infinity system (Santa Clara, CA, USA). A Waters XBridge BEH 300 C4 $(4.6 \mathrm{~mm} \times 150 \mathrm{~mm}, 3.5-\mu \mathrm{m}$ particle size) column was used to separate analytes at a flow rate of $1.44 \mathrm{ml} / \mathrm{min}$. The mobile phase was $0.1 \%$ trifluoroacetic acid (TFA) in water (Eluent A) and $0.1 \%$ TFA in acetonitrile (Eluent $B$ ) applied in gradient mode: $0-18$ min, a linear increase from 20 to $80 \%$ Eluent $\mathrm{B} ; 18-30 \mathrm{~min}$, washing, and reequilibration. The injection concentration and volume were the same as those used for SEC. The intact masses of the antibody were determined with RP-HPLC using a Waters Acquity I class UPLC system. Separation was performed on a Thermo MabPac ${ }^{\mathrm{TM}} \mathrm{RP}$ column $(2.1 \mathrm{~mm} \times 50 \mathrm{~mm}, 4-\mu \mathrm{m}$ particle size) at a flow rate of $0.2 \mathrm{ml} / \mathrm{min}$. The mobile phase was prepared by mixing $0.1 \%$ formic acid in water (Eluent A) and $0.1 \%$ formic acid in acetonitrile (Eluent B). After linear gradient elution for $2 \mathrm{~min}$ with an increase in the ratio of Eluent $B$ to $25 \%$ followed by isocratic elution with $25 \%$ Eluent B, the sample was separated by linear gradient elution (25-45\% Eluent B). The effluent was analyzed with a Thermo Fisher LTQ Orbitrap mass spectrometer (Thousand Oaks, CA, USA) using Fourier transform (FT) mode. The resolution and mass range of the FT-based mass spectrometer were 120,000 and $m / z 400-4000$, respectively. The injection concentration and volume were $0.1 \mathrm{mg} / \mathrm{ml}$ and $5 \mu \mathrm{l}$, respectively. Glycan profiling was performed with a Rapi-Fluor labeling kit (Waters, Milford, MA, USA), and all procedures were performed as described previously ${ }^{27,28}$.

\section{ELISA}

For coating, $50 \mu \mathrm{l}$ of $\mathrm{G}_{\mathrm{ai3}}\left(4 \mu \mathrm{g} / \mathrm{ml}\right.$, diluted in $0.05 \mathrm{M} \mathrm{Na}_{2} \mathrm{CO}_{3}$ (pH 9.6)) was added to a 96-well polystyrene plate, and the plate was incubated at $4{ }^{\circ} \mathrm{C}$ for $16 \mathrm{~h}$. After the addition of $150 \mu \mathrm{l}$ of $4 \%$ skim milk in $1 \times \mathrm{PBS}(\mathrm{pH} 7.4)$ and incubation for $2 \mathrm{~h}$ for blocking, $50 \mu \mathrm{l}$ of $4 \mu \mathrm{g} / \mathrm{ml} \mathrm{hET} / \mathrm{mET}_{\mathrm{A}}$ reconstituted in $0.5 \%$ sarkosyl was added to the plate. Then, the plate was washed four times with $150 \mu \mathrm{l}$ of $1 \times$ PBS containing $0.05 \%$ Tween 20 (PBST, pH 7.4), and $50 \mu \mathrm{l}$ of AG8 lgG serially diluted in 1X PBS (pH 7.4) was added. After the plate was washed with $150 \mu \mathrm{l}$ of PBST, $50 \mu \mathrm{l}$ of a goat anti-human lgG $(\mathrm{H}+\mathrm{L})$ antibody-HRP conjugate (5000-fold dilution; Thermo Fisher Scientific, Waltham, MA, USA) was added. After the plate was washed 
with $150 \mu$ l of PBST, $50 \mu$ l of $1-$ Step $^{\mathrm{TM}}$ Ultra TMB was added, the plate was incubated for $20 \mathrm{~min}$, and $50 \mu \mathrm{l}$ of $4 \mathrm{~N} \mathrm{H}_{2} \mathrm{SO}_{4}$ was added to the wells to quench the ELISA signal. The absorbance at $450 \mathrm{~nm}$ was analyzed in an Epoch plate reader (BioTek, Winooski, VT, USA).

\section{Calcium flux assay}

Changes in the cytosolic $\mathrm{Ca}^{2+}$ concentration upon $\mathrm{hET}_{\mathrm{A}}$ binding to the ET-1 ligand were analyzed as described in the literature ${ }^{29}$. After incubation of $1 \times 10^{5} \mathrm{hET}_{\mathrm{A}}$-overexpressing CHO-K1 cells or HT-29 colorectal cancer cells with $5 \mu \mathrm{M}$ fura-2-acetoxymethyl ester (Fura-2-AM) dye at $25^{\circ} \mathrm{C}$ for $1 \mathrm{~h}$, serially diluted scAb AG8 was added. After incubation at $25^{\circ} \mathrm{C}$ for $1 \mathrm{~h}, 10 \mathrm{nM}$ ET-1 was added, and the resulting fluorescence emission at $510 \mathrm{~nm}$, with separate excitation at 380 and $340 \mathrm{~nm}$, was monitored using a FluoroMate FS-2 fluorescence spectrometer (Scinco, Seoul, Korea) to evaluate the $\mathrm{Ca}^{2+}$ concentration changes upon intracellular endothelin signaling.

\section{Proliferation assay}

Cancer cell proliferation was analyzed using a CyQUANT ${ }^{\mathrm{TM}}$ NF cell proliferation kit (Thermo Fisher Scientific, Waltham, MA, USA). Cells were seeded in 96-well plates at a density of $2-3 \times 10^{3}$ cells/well. After $24 \mathrm{~h}$ of incubation, $\mathrm{ET}-1$ and the anti-ET $\mathrm{A}_{\mathrm{A}}$ antibody were mixed at a 1:1 ratio in $2 \%$ FBS medium, and the medium was replaced with RPMI-1640 medium. After $24 \mathrm{~h}$, CyQUANT ${ }^{\circ} \mathrm{NF}$ dye reagent was added, and the cells were incubated at $37^{\circ} \mathrm{C}$ for $30 \mathrm{~min}$. Then, the fluorescence intensity was measured as the ratio of the fluorescence at $530 \mathrm{~nm}$ to that at $485 \mathrm{~nm}$ using an Infinite M200 Pro microplate reader (TECAN, Männedorf, Switzerland).

\begin{abstract}
Western blot analysis
Whole-cell protein lysates were prepared using RIPA buffer (iNtRON Biotechnology, Seongnam, Korea) supplemented with protease inhibitor cocktail (Roche, Basel, Switzerland), and total protein samples were quantified using a BCA Protein Assay Kit (Thermo Fisher Scientific, Waltham, MA, USA). After separation of equal amounts of the protein lysates on $10 \%$ Bis-Tris protein gels (Thermo Fisher Scientific, Waltham, MA, USA), transfer to PVDF membranes (Merck Millipore, USA), and blocking with $5 \%$ skim milk, the membranes were incubated with HRPconjugated anti- $\beta$-actin, anti-phospho-ERK1/2, anti-total-ERK1/2, antiphospho-AKT (S473), or anti-total-AKT antibodies (Cell Signaling Technology, Danvers, MA, USA). Then, the membranes were washed in $0.05 \%$ Tween 20 in Tris-buffered saline and incubated with a 1:5000 dilution of anti-rabbit IgG -HRP conjugate (Bio-Rad, USA) as the secondary antibody. Specific bands were detected using a WEST-ZOL plus Western Blot Detection System (iNtRON Biotechnology, Seongnam, Korea).
\end{abstract}

\section{RNA extraction and quantitative real-time PCR (qRT-PCR) analysis}

The total RNA was isolated using an RNeasy Mini Kit (Qiagen, Germantown, $M D$, USA) following the manufacturer's protocol. Reverse transcription was conducted using $1 \mu \mathrm{g}$ of total RNA as a template and SuperScript ${ }^{\mathrm{TM}}$ III Reverse Transcriptase (Thermo Fisher Scientific, Waltham, MA, USA). qRT-PCR was performed in triplicate in LightCycler 480 system with SYBR Green I Master Mix (Roche, Mannheim, Germany) and the appropriate primers (MSJ\#50/MSJ\#51), and the target gene expression levels were normalized to the $\beta$-actin level. The values from independent experiments were averaged, and are presented as the means \pm standard deviations.

\section{Mouse xenograft model}

The animal study was reviewed and approved by the Institutional Animal Care and Use Committee (IACUC) of the National Cancer Center Research Institute (NCCRI). The NCCRI is an Association for Assessment and Accreditation of Laboratory Animal Care International (AAALAC International)-accredited facility and abides by the Institute of Laboratory Resources (ILAR) guidelines. Five-week-old female nude mice (BALB/C nude) were purchased from OrientBio (Seongnam, Korea). After 1 week, colorectal cancer cells $\left(2 \times 10^{6}\right)$ resuspended in $100 \mu$ l of $1 \times$ PBS (pH 7.4) were subcutaneously injected using a 31-gauge needle. The tumor-bearing mice were randomized into the control and treatment groups $(n=4$ mice per group) after 7 days. Then, AG8 $\mathrm{lgG}(1.125 \mathrm{mg} / \mathrm{kg})$ was injected intratumorally into each mouse at 2-day intervals, and $1 \times \mathrm{PBS}(\mathrm{pH} 7.4$, $50 \mu \mathrm{l} /$ mouse) was injected as the negative control. After tumor volumes and body weights were measured prior to antibody injection, the tumors were measured using a caliper, and the volumes were calculated as follows: $[W$ (width $) 2 \times L$ (length) $] \times 1 / 2$. The mice were sacrificed 27 days after cancer cell injection.

\section{Statistical analysis}

Statistical analyses were performed with Student's $t$ test, and $P<0.05$ was considered statistically significant.

\section{In silico modeling to predict the AG8 binding site in $\mathbf{E T}_{\mathrm{A}}$}

Structural modeling of the single-chain variable fragment antibody (scFv) was carried out using the AG8 sequence and the antibody modeling tool of the Discovery Studio 2019 program (Biovia, San Diego, CA, USA). The crystal structures for $\mathrm{ET}_{\mathrm{B}}$ from the Protein Data Bank (PDB IDs: 5GLI and $5 \mathrm{GLH}$ for ligand-free $\mathrm{hET}_{\mathrm{B}}$ and $\mathrm{ET}$-1-bound $\mathrm{ET}_{\mathrm{B}}$, respectively) were used for modeling and docking analysis. The potential binding site in AG8 was limited to the extracellular region of the $\mathrm{ET}_{\mathrm{B}}$ structure, and the most stable binding site was determined using the "ZDOCK" function in Discovery Studio $2019^{30}$.

\section{RESULTS \\ Preparation of functional $\mathrm{hET}_{\mathrm{A}}$ antigens mimicking the structure of native $\mathrm{hET}_{\mathrm{A}}$ on the cell membrane}

For screening of monoclonal human antibodies against $\mathrm{hET}_{A}$, it is necessary to prepare a sufficient amount of functional antigen structurally similar to native $\mathrm{hET}_{\mathrm{A}}$. However, it is well known that the complex structure of GPCRs, with seven transmembrane ahelices, is difficult to express in heterologous hosts ${ }^{31}$. In a previous study, we overexpressed $\mathrm{hET}_{\mathrm{A}}$ in $E$. coli by fusion of the P9 sequence of Pseudomonas phage $\Phi 6$ (Phi6) to the N-terminal region of $h E T_{A}$ (Fig. 1a) ${ }^{20}$. As reported in the previous work, both $\mathrm{hET}_{\mathrm{A}}$ and $\mathrm{mET}_{\mathrm{A}}$ were successfully overexpressed in $E$. coli through the fusion of the N-terminal P9 motif, and they were purified from sarkosyl-solubilized cell membrane fractions using Ni-NTA affinity chromatography (Fig. 1b, c). In an ELISA, purified hET $_{\mathrm{A}}$ showed binding affinity not only for its ligand ET-1 but also for human $\mathrm{G}_{\mathrm{ai}}$, which is an essential component of GPCR downstream signaling ${ }^{8}$ (Fig. 1d, e). To prepare a functional $\mathrm{hET}_{\mathrm{A}}$ antigen with a native-like structure, we reconstituted purified $\mathrm{hET}_{\mathrm{A}}, \mathrm{MSP}-1$, and lipids in an optimized ratio, and antigen-embedded nanodiscs were successfully recovered by size-exclusion chromatography (SEC) (Fig. 1f-h).

\section{Isolation of a human $\mathrm{ET}_{\mathrm{A}}$-specific antibody using a constructed human antibody library and immobilized $\mathbf{h E T}_{A}$ nanodiscs}

To isolate a specific $\mathrm{ET}_{\mathrm{A}}$ human antibody, we constructed a phage library displaying human SCFv antibodies (library size: $>1 \times 10^{10}$ individual clones, as estimated from the number of transformants) by $\mathrm{PCR}$ amplification of $\mathrm{VH}$ and $\mathrm{VL}$ genes existing in the immune repertoire of human $B$ cells (Fig. $2 a$ ). The purified $\mathrm{hET}_{\mathrm{A}}$ nanodiscs were immobilized on the plate in an orientation-controlled manner through capture by precoated human $G_{\text {ai3 }}$ so that the scFv antibodies could efficiently access the extracellular region of $\mathrm{hET}_{\mathrm{A}}$. After five rounds of negative screening of the phage library against empty nanodiscs and biopanning against immobilized $\mathrm{hET}_{\mathrm{A}}$ nanodiscs with increasing numbers of washing cycles in successive screening rounds (Fig. 2b), we observed that phages displaying a high affinity for $\mathrm{hET}_{\mathrm{A}}$ nanodiscs were enriched based on the output phage titers (Supplementary Table 3). As determined by phage ELISA, five individual clones exhibited a high signal for binding to the $\mathrm{hET}_{\mathrm{A}}$ nanodisc, and DNA sequencing of the five clones revealed that all had the same ScFv sequence (Fig. 2c), suggesting successful enrichment of a particular human antibody clone via the $\mathrm{hET}_{\mathrm{A}}$ affinity-based screening system. Next, we aligned the sequences of the variable regions of the scFv antibody (AG8) with the germline sequences of those of human immunoglobulins using IMGT/V-QUEST ${ }^{32}$. The sequence analysis results revealed a sequence identity of $94.44 \%$ between the VH region of $A G 8$ and the human immunoglobulin heavy-chain 
a

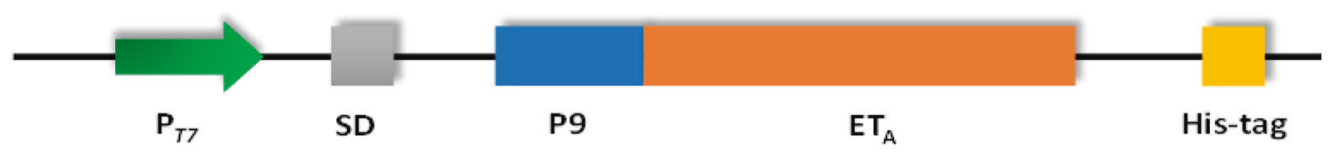

b

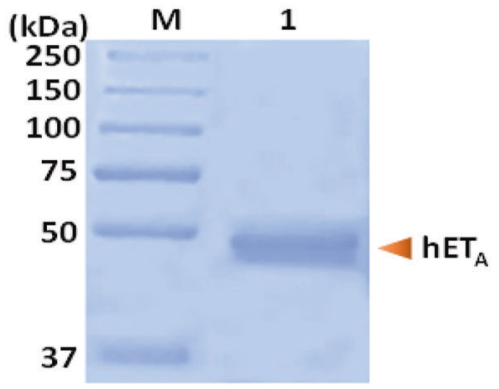

d

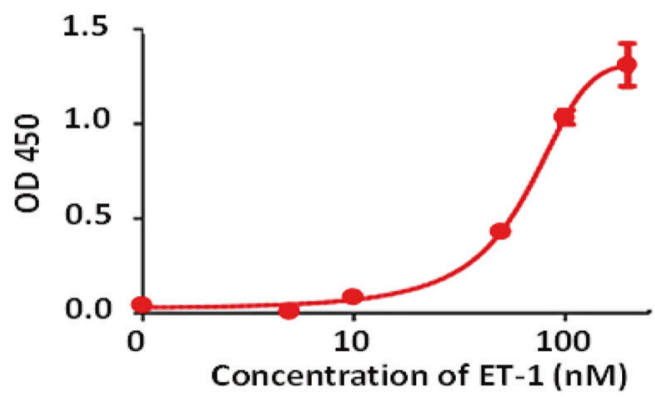

c

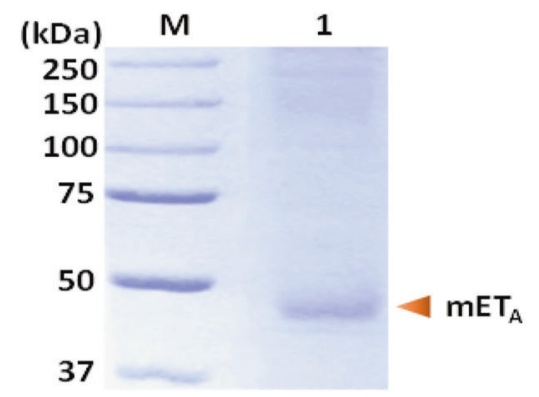

e

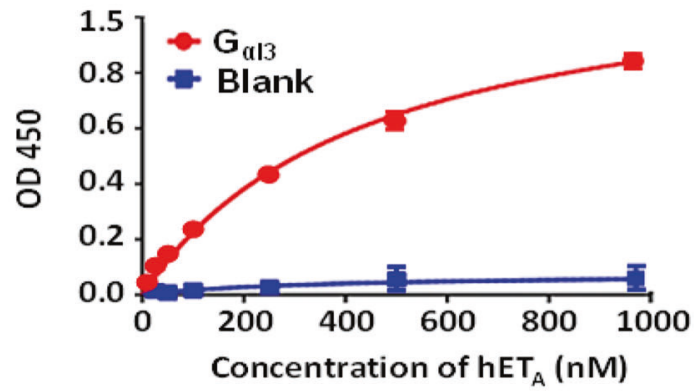

f

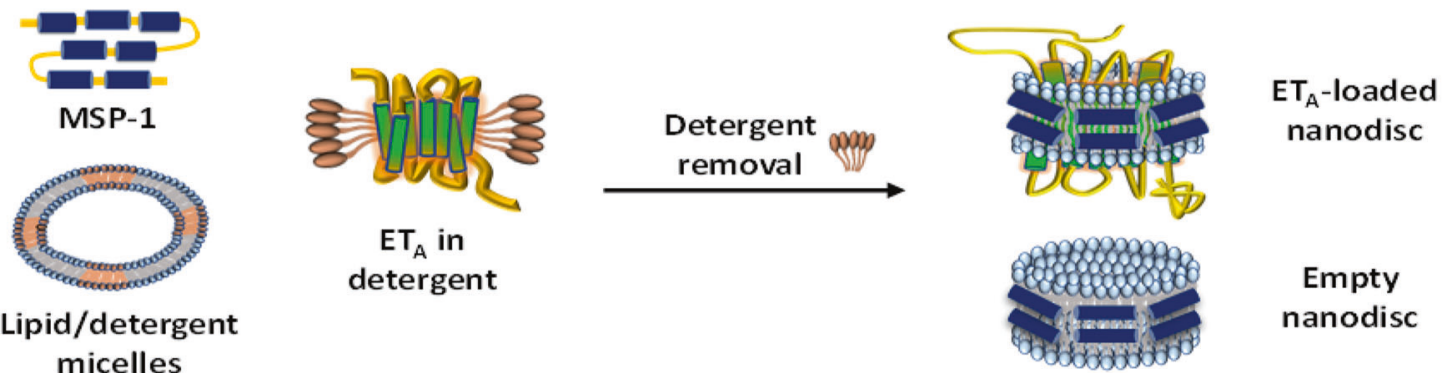

g

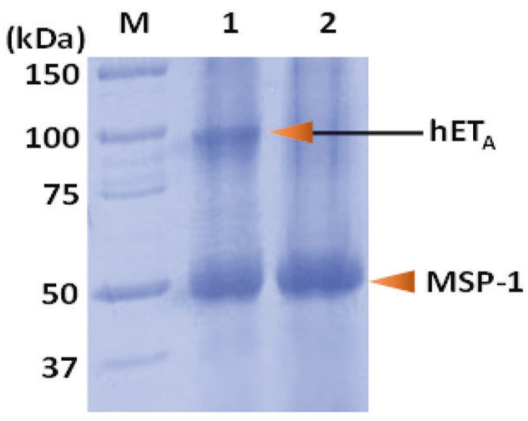

h

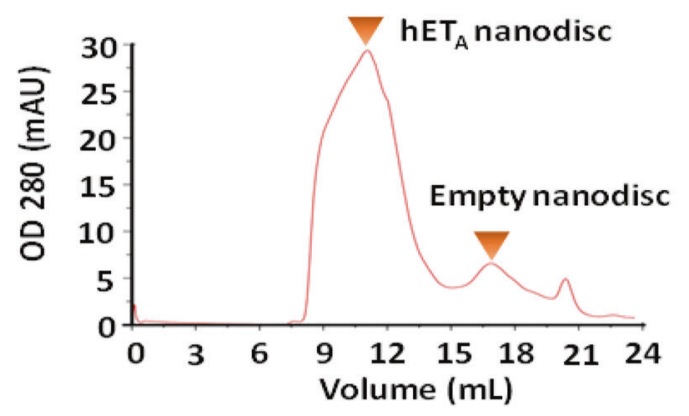

Fig. 1 Preparation of the ET $_{A}$ antigen for isolation of an anti-hET $T_{A}$ antibody. a Expression cassette for endothelin receptor type $A$. b, c SDS-PAGE gel images showing purified human $\mathrm{ET}_{\mathrm{A}}\left(\mathrm{hET}_{\mathrm{A}}\right)(\mathbf{b})$ and mouse $\mathrm{ET}_{\mathrm{A}}\left(\mathrm{mET}_{\mathrm{A}}\right)$ (c). d, e ELISA results showing the binding of purified $\mathrm{hET}_{\mathrm{A}}$ to its ligands ET-1 (d) and $\mathrm{G}_{\alpha i 3}$ (e). f Overall scheme showing the method for preparing reconstituted $\mathrm{ET}_{\mathrm{A}}$ nanodiscs and empty nanodiscs. g, $\mathbf{h}$ SDS-PAGE gel image (g) and gel filtration chromatogram (h) showing the hET $_{\mathrm{A}}$ nanodisc and empty nanodisc fractions; Lane 1: $\mathrm{hET}_{\mathrm{A}}$ nanodisc fraction; Lane 2: empty nanodisc fraction. 
a

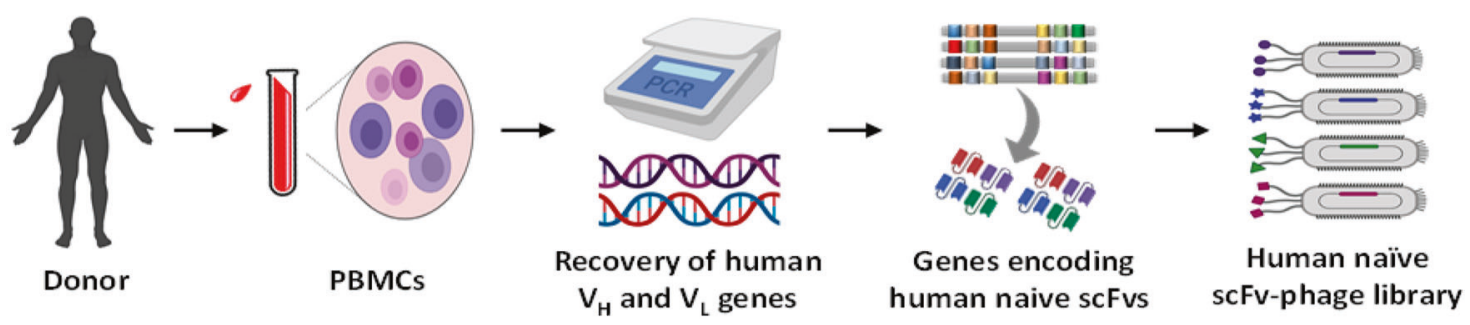

b
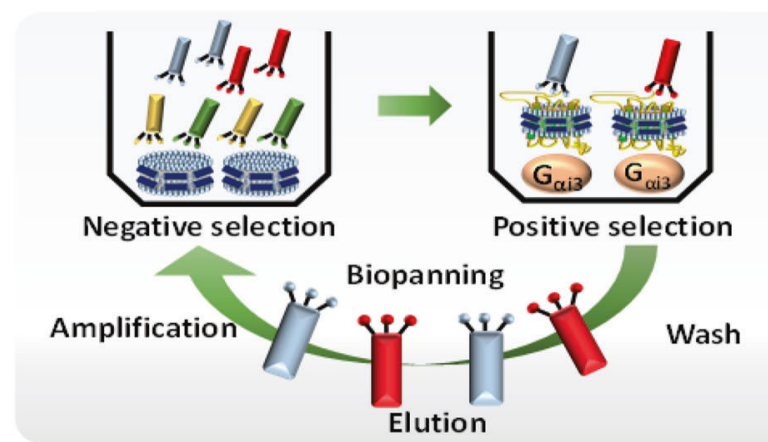

c

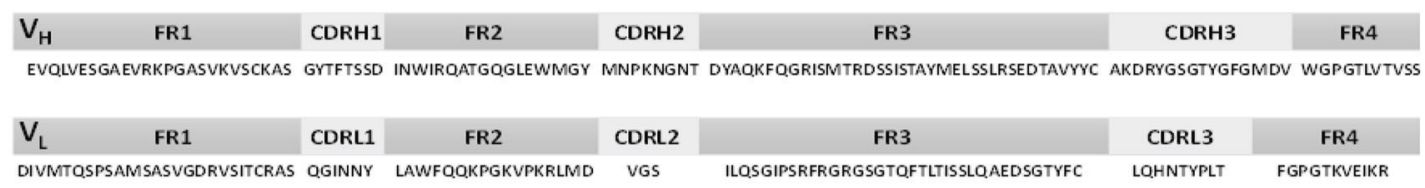

d

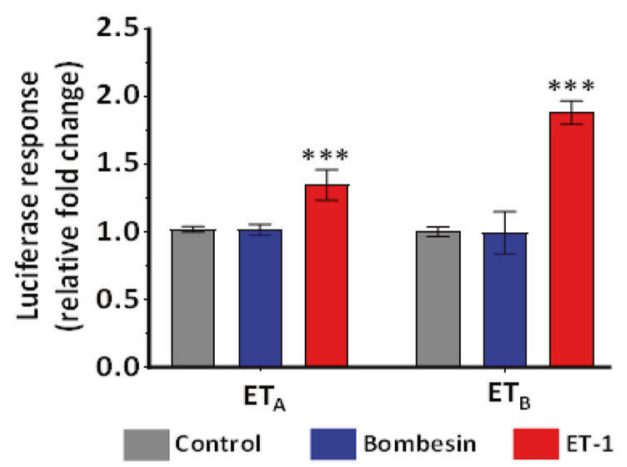

e

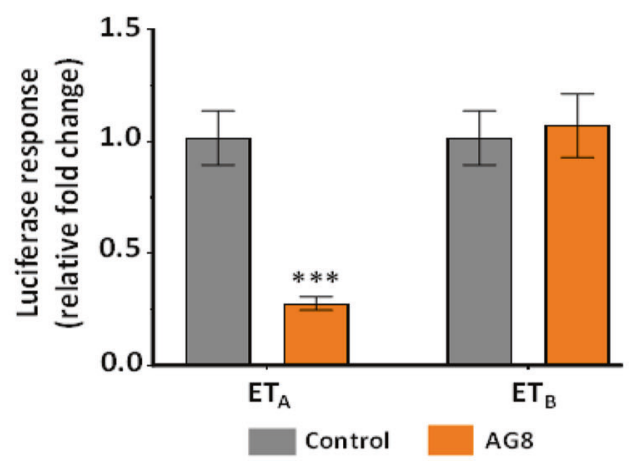

Fig. 2 Analysis of protein sequence and endothelin receptor specificity for AG8. a, b Overall scheme showing the processes for constructing the human naïve SCFv antibody library (a) and screening for the anti-ET $\mathrm{A}_{\mathrm{A}}$ antibody using the phage display system (b). c Amino acid sequences of the framework and complementarity-determining regions in AG8. $\mathbf{d} \beta$-Arrestin Tango recruitment assay using bombesin and ET-1 in cells that express $\mathrm{ET}_{\mathrm{A}} / \mathrm{ET}_{\mathrm{B}}$ receptors. e $\beta$-Arrestin Tango recruitment assay using M13 phage particles displaying AG8 scFv. The error bars show the mean \pm standard deviation values; ${ }^{*} P \leq 0.05,{ }^{* *} P \leq 0.01,{ }^{* * *} P \leq 0.001$ vs. control.

variable region V1-8 genes (IMGT ID: M99637), and the sequence of the AG8 VL light chain was $90.68 \%$ identical to that of the human immunoglobulin kappa chain variable region $\mathrm{V} 1-17$ genes (IMGT ID: KM455566).

\section{AG8 exerts antagonistic effects on ET-1-induced signaling of $\mathrm{hET}_{\mathrm{A}}$}

For analysis of the antagonistic effects of the isolated antibody on ET-1-induced $\mathrm{hET}_{\mathrm{A}}$ signaling, we employed a $\beta$-arrestin Tango assay that enabled monitoring of $\beta$-arrestin recruitment through luciferase gene expression ${ }^{33}$. In cells that expressed both $\mathrm{hET}_{A}$ and $\mathrm{hET}_{\mathrm{B}}$, luciferase expression was not activated in the control group treated with bombesin, a ligand unrelated to both $\mathrm{hET}_{A}$ and $\mathrm{hET}_{\mathrm{B}}$; however, the presence of ET-1, a native ligand for both $\mathrm{hET}_{A}$ and $\mathrm{hET}_{\mathrm{B}}$, activated luciferase expression (Fig. 2d). As expected, the addition of phage particles displaying the isolated AG8 SCFv inhibited luciferase expression by up to $72 \%$ in $\mathrm{hET}_{\mathrm{A}}$-expressing cells. In sharp contrast, cells expressing $\mathrm{hET}_{B}$, which shares the 
a

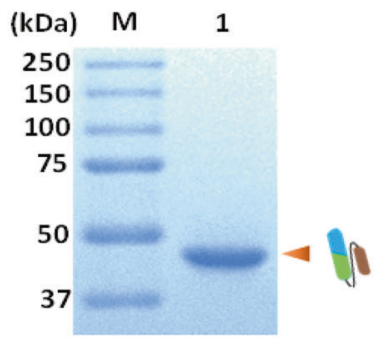

d

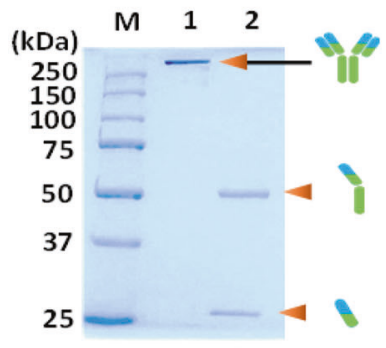

b

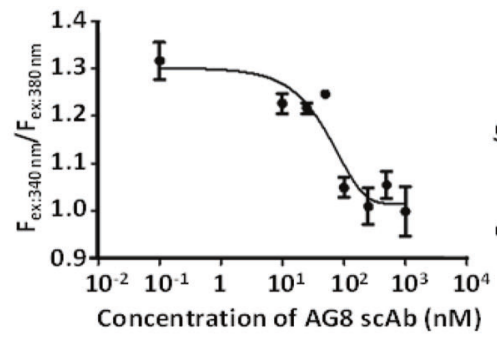

C

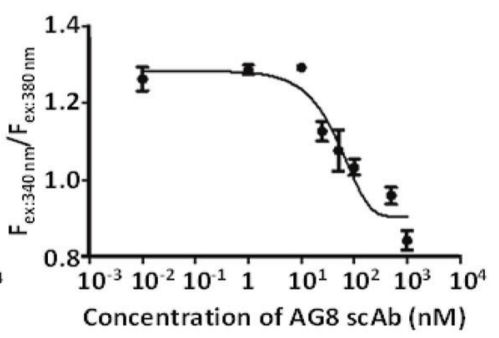

e

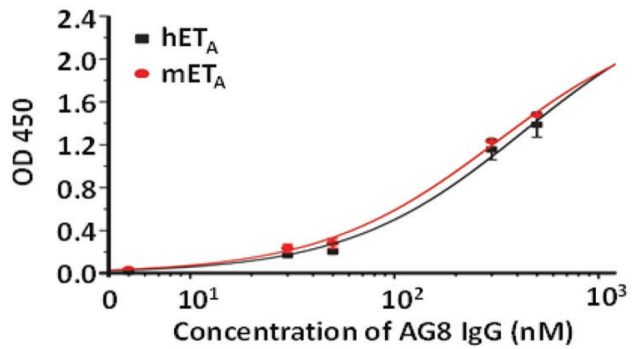

Fig. 3 Purification and characterization of AG8. a SDS-PAGE gel showing the band for the purified scAb AG8. b, c Calcium flux assay with the scAb AG8 in CHO-K1 cells expressing hET $_{A}(\mathbf{b})$ and in HT-29 cells (c). d SDS-PAGE showing purified AG8 IgG. e ELISA showing the cross-species binding property of $\mathrm{AG} 8 \mathrm{IgG}$ to human $\mathrm{ET}_{\mathrm{A}}$ and mouse $\mathrm{ET}_{\mathrm{A}}$.

capacity for $\mathrm{ET}-1$ binding with $\mathrm{hET}_{\mathrm{A}}$, did not exhibit a reduction in luciferase expression upon treatment with the same phage particles, indicating that the resulting AG8 is highly specific for a particular isotype of $\mathrm{hET}_{\mathrm{A}}$ rather than an isotype of $\mathrm{hET}_{\mathrm{B}}$ (Fig. 2e). To investigate whether purified AG8 can regulate the function of $\mathrm{hET}_{\mathrm{A}}$, we expressed the isolated antibody in $E$. coli as a singlechain antibody (scAb) that contained a human kappa light-chain constant (HuCK) domain and purified it via affinity chromatography using KappaSelect resin (Cytiva, Marlborough, MA, USA) (Fig. 3a). Then, the antagonistic effect of $A G 8$ on $h_{E T}$ was analyzed using fura-2-acetoxymethyl ester (fura-2 AM), a ratiometric calcium indicator, to analyze ET-1-binding-triggered $\mathrm{hET}_{\mathrm{A}}$ activation, which can be monitored by measuring the increase in the intracellular $\mathrm{Ca}^{2+}$ level mediated through the inositol trisphosphate (IP3) pathway ${ }^{34}$. In both $\mathrm{hET}_{\mathrm{A}}$-expressing $\mathrm{CHO}-\mathrm{K} 1$ cells treated with $10 \mathrm{nM}$ ET-1 and HT-29 colorectal cancer cells treated with the same concentration of ET-1, the scAb AG8 inhibited the ET-1-induced increase in the intracellular $\mathrm{Ca}^{2+}$ level, as evidenced by the $\mathrm{IC}_{50}$ values $(56 \mathrm{nM}$ in CHO-K1 cells and $51 \mathrm{nM}$ in HT-29 cells). These results clearly demonstrate that AG8 exerted an antagonistic effect on ET-1 ligand binding-mediated $h E T_{A}$ signaling (Fig. 3b, c).

The cross-species high binding affinity of AG8 IgG for human $\mathrm{ET}_{\mathrm{A}}$ and mouse $\mathrm{ET}_{\mathrm{A}}$

To verify the cross-species binding affinity of AG8 lgG for human and mouse $\mathrm{ET}_{\mathrm{A}}$ antigens, $\mathrm{AG} 8$ was expressed in a full-length $\mathrm{lgG}$ form in Expi293 mammalian cells and purified via Protein A affinity chromatography (Fig. 3d). The cross-species binding of AG8 IgG was verified by ELISAs using purified human or mouse $E_{A}$ captured by human $\mathrm{G}_{\text {ais }}$ that was preimmobilized on ELISA plates. Considering that the protein sequence of the mouse $\mathrm{ET}_{\mathrm{A}}$ antigen is $94.3 \%$ identical to that of human $\mathrm{ET}_{\mathrm{A}}$, we reasoned that $\mathrm{AG} 8 \mathrm{IgG}$ would show a binding affinity for both $\mathrm{hET}_{\mathrm{A}}$ and $\mathrm{mET}_{\mathrm{A}}$ proteins. As expected, the apparent binding affinities of AG8 IgG for human and mouse $\mathrm{ET}_{\mathrm{A}}$ were almost identical in the ELISAs (Fig. 3e).

\section{Physicochemical properties of AG8 IgG}

The physicochemical properties of AG8 IgG were characterized by four methods, as shown in Fig. 4. The percentages of the monomeric and aggregated forms of AG8 lgG were $95.23 \%$ and $4.77 \%$, respectively, and no other impurities were detected in RPHPLC analysis. The molecular weight of AG8 lgG was measured both with and without PNGase $F$ treatment, and the accuracies were $<1 \mathrm{Da}$. The glycan profile of AG8 IgG was slightly different from that of the IgG standard, but the result was similar to those shown in other reports ${ }^{27,28}$. No analyzed physicochemical properties created an issue for subsequent in vitro and in vivo assays.

\section{In vitro effects of AG8 IgG on cancer cells}

Human $\mathrm{ET}_{\mathrm{A}}$ is an important target for cancer treatment because it is highly involved in several signaling pathways that promote cell proliferation, metastasis, and neovascularization ${ }^{34}$. In particular, a high correlation between $\mathrm{hET}_{\mathrm{A}}$ overexpression and the progression of colorectal cancer has been reported ${ }^{35}$. In two colorectal cancer cell lines, HT-29 and HCT-116, AG8 lgG reduced the proliferation of cells by up to $40 \%$ (Figs. $5 \mathrm{a}$ and $5 \mathrm{~b}$ ). To investigate how AG8 lgG inhibited the proliferation of these cells, we performed western blot analyses to measure the phosphorylation levels of downstream signaling pathway components. It has been well established that ET-1 binding to $\mathrm{hET}_{\mathrm{A}}$ promotes the phosphorylation of ERK and AKT in colorectal cancer cells ${ }^{36,37}$. We found that the addition of AG8 IgG significantly reduced ET-1induced phosphorylation of both ERK and AKT in cancer cells (Fig. $5 c$ ). Furthermore, transcription of inhibin $\beta A$ (INHBA), which is activated by ET-1 binding to $\mathrm{hET}_{\mathrm{A}}$, was decreased upon treatment with AG8 lgG (Fig. 5d). Taken together, these results indicate that the specific binding of AG8 IgG to $\mathrm{hET}_{\mathrm{A}}$ blocks downstream $\mathrm{hET}_{\mathrm{A}}$ signaling and inhibits colorectal cancer cell proliferation.

Inhibition of tumor growth by AG8 IgG in BALB/c nude mice We next confirmed the anticancer effects of AG8 IgG in vivo. A xenograft mouse model was established by subcutaneous injection of colorectal cancer cells into the flanks of BALB/c nude 


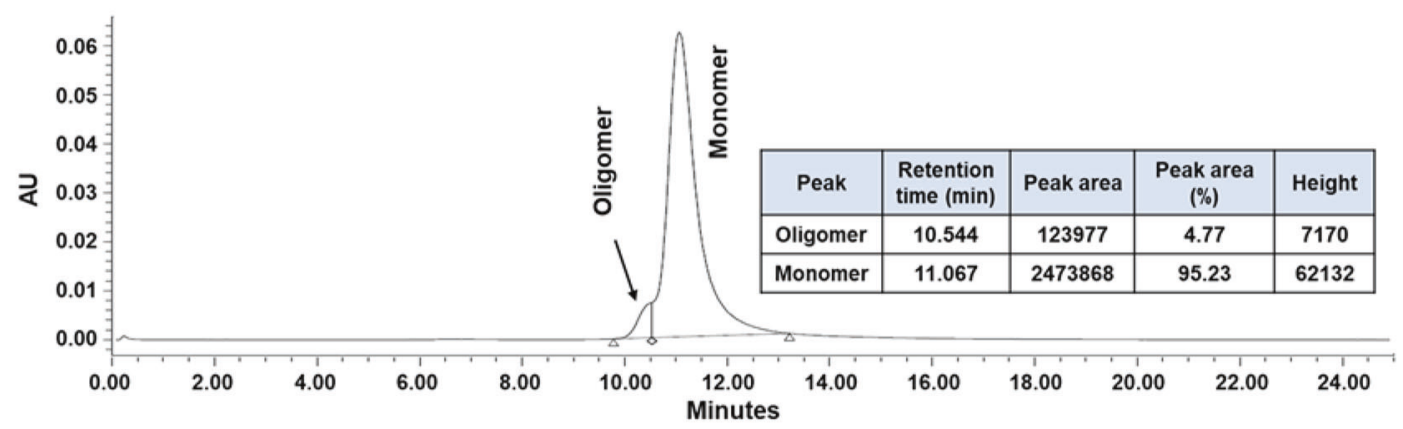

b

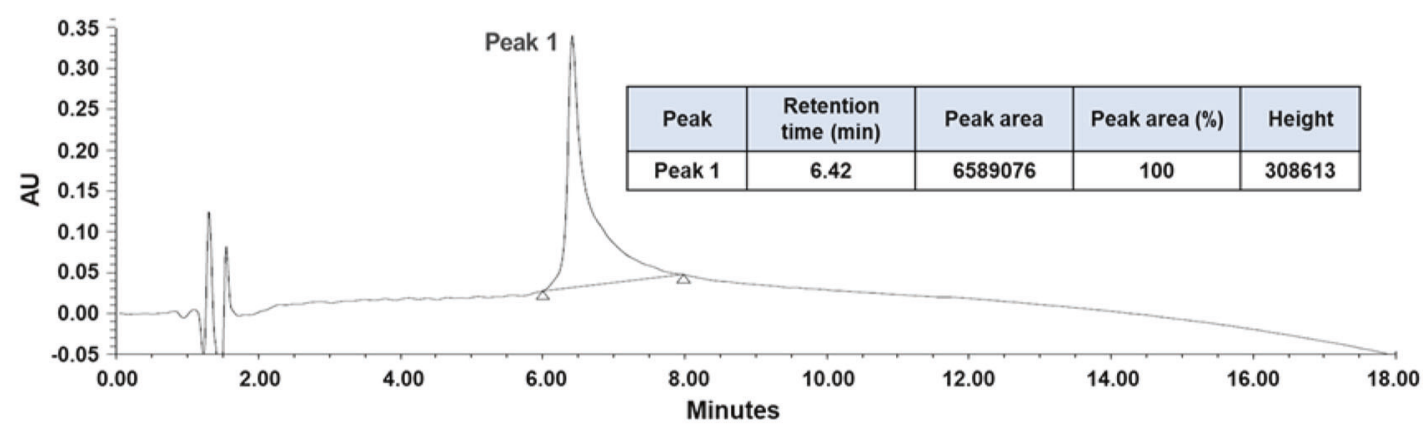

C
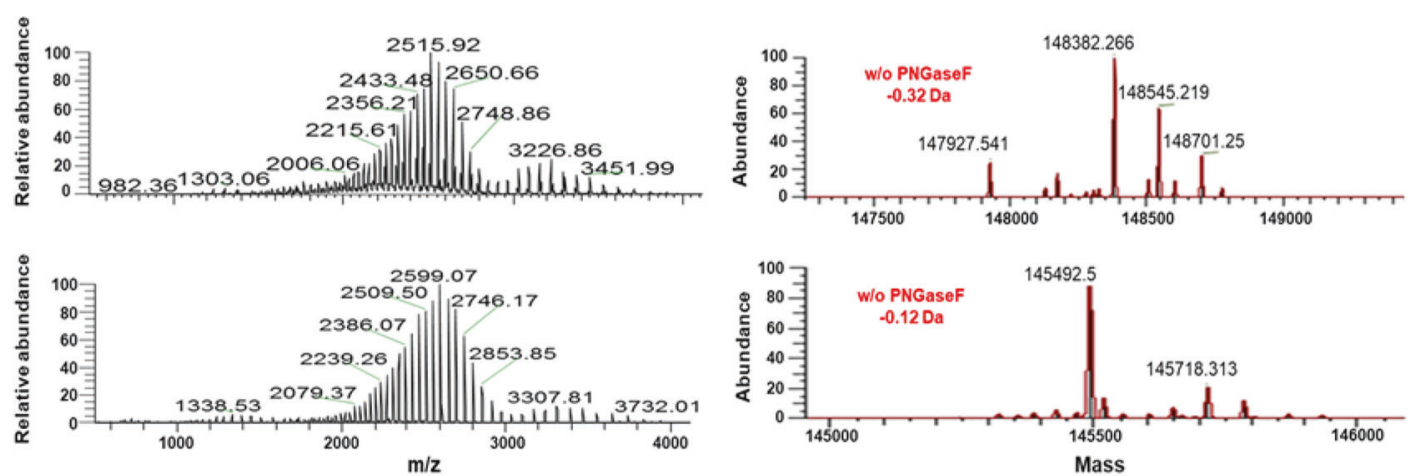

d

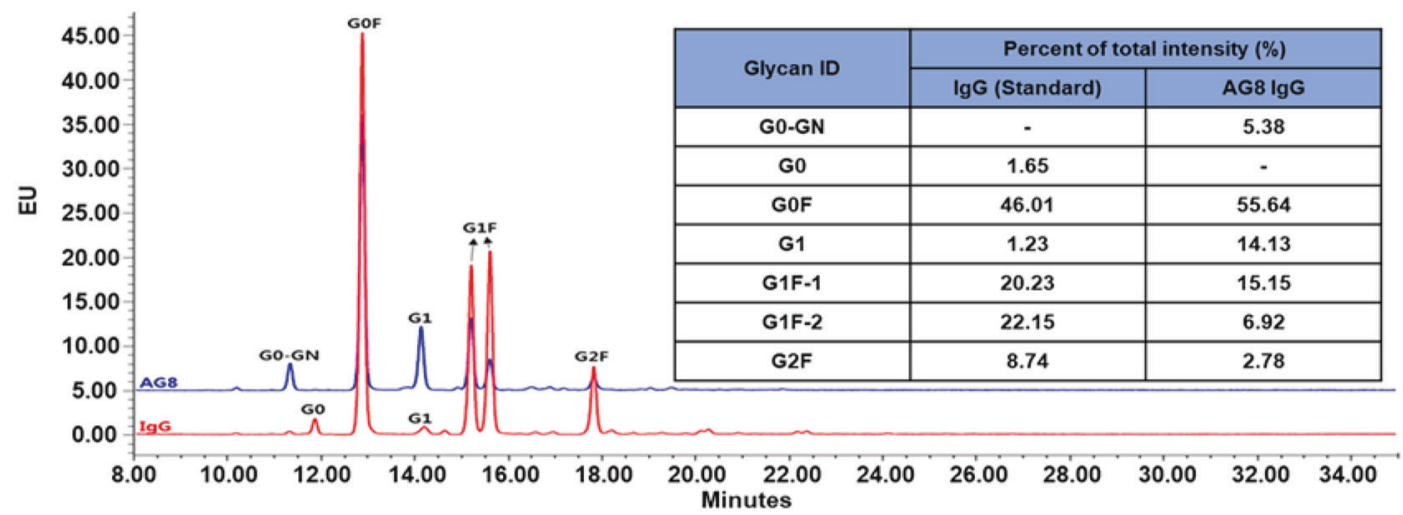

Fig. 4 Physicochemical characterization of AG8. a SEC analysis of the oligomer proportions of purified AG8 IgG. b RP-HPLC chromatogram generated to analyze the purity of AG8 lgG. c Intact mass analysis for purified AG8 lgG. d HPLC analysis for glycan profiling of AG8 IgG.

mice, and AG8 lgG was administered at 2-day intervals by intratumoral injection $(1.125 \mathrm{mg} / \mathrm{kg}$ per injection). After 27 days, tumor growth in the AG8-treated mice was decreased $40 \%$ relative to that in PBS-treated mice (Fig. 5e, f), clearly showing that AG8 lgG exerted significant antitumor effects in mice bearing colorectal cancer xenografts. 


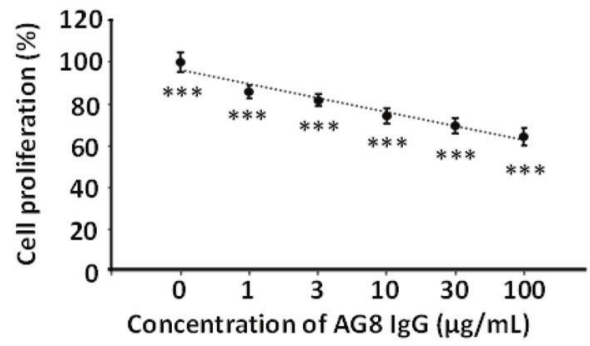

b

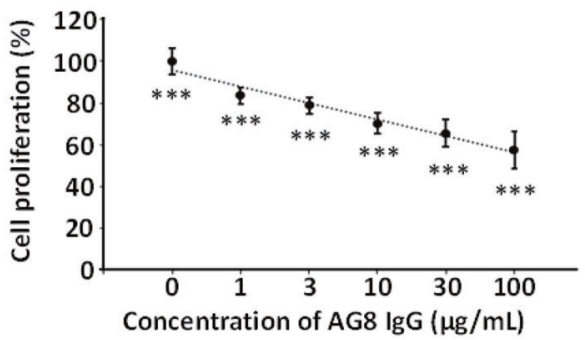

d

C

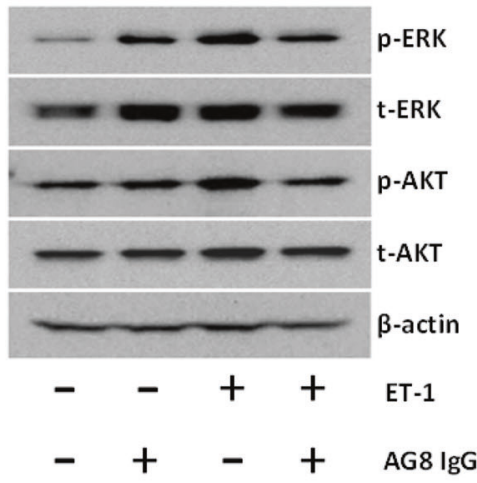

e

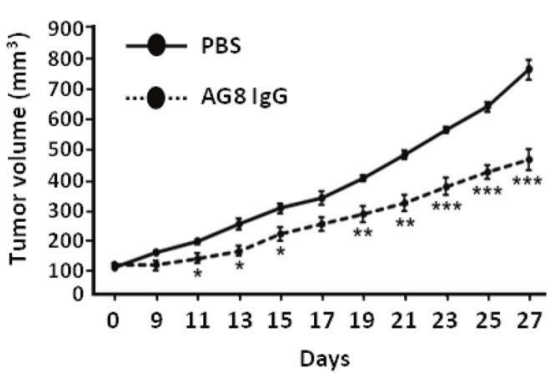

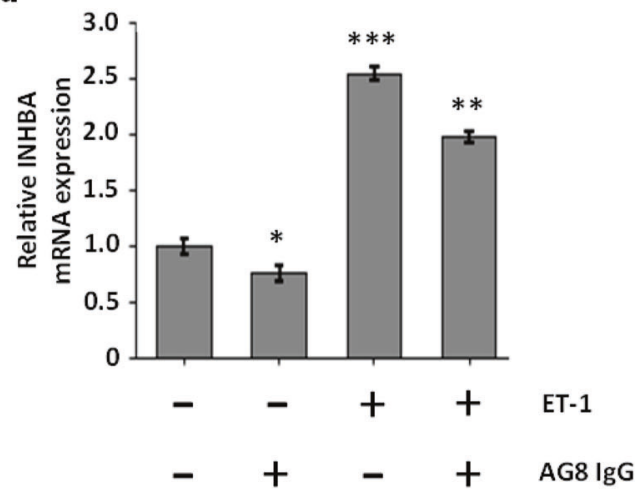

$\mathbf{f}$

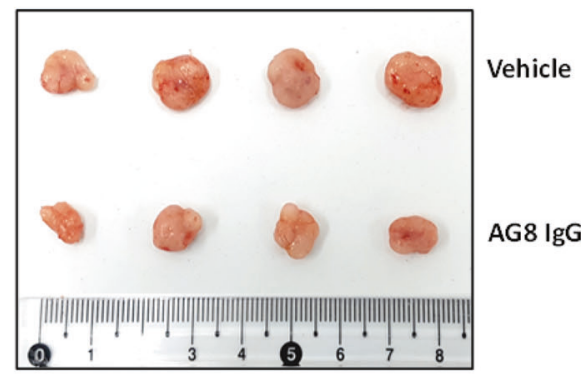

Fig. 5 Anti-hET AG8 suppressed the growth of colorectal cancer cells. a, b Inhibition of the proliferation of colorectal cancer cells (HT-29 (a) and HCT-116 (b)) treated with AG8 IgG. Cancer cells were seeded in 96-well plates in the presence of AG8 and incubated for $72 \mathrm{~h}$. c Western blot analysis of phosphorylated AKT and ERK levels in HCT-116 colorectal cancer cells treated with ET-1 (10 nM) for 10 min with or without pretreatment with AG8 $(100 \mu \mathrm{g})$ for $4 \mathrm{~h}$. $\beta$-Actin was used as the loading control. d The mRNA expression of INHBA in HCT-116 cells treated with ET-1 $(10 \mathrm{nM})$ for $24 \mathrm{~h}$ with or without pretreatment with AG8 $(100 \mu \mathrm{g})$ for $4 \mathrm{~h}$. e HT-29 cells were subcutaneously injected into nude mice. Tumor-bearing mice were randomized, and AG8 $(1.125 \mathrm{mg} / \mathrm{kg})$ was intratumorally injected into each mouse at intervals of 2 days. $\mathbf{f}$ Photos of dissected tumor masses on Day 27 . The error bars show the mean \pm standard deviation values; ${ }^{*} P \leq 0.05,{ }^{* *} P \leq 0.01,{ }^{* * *} P \leq 0.001$ vs. control.

\section{In silico modeling of the structure of AG8}

Comparison of the sequences of the $\mathrm{hET}_{\mathrm{A}}$ (UniProtKB ID: P25101) and $\mathrm{hET}_{B}$ (UniProtKB ID: P24530) proteins determined their sequence identity and similarity to be $53.9 \%$ and $71.8 \%$, respectively. To infer the structure of $\mathrm{hET}_{\mathrm{A}}$, for which no crystal structure is available, two crystal structures (PDB codes: $5 \mathrm{GLI}$ and $5 G L H$ for ligand-free $h \mathrm{hT}_{B}$ and $E T-1$-bound $\mathrm{ET}_{B}$, respectively) were used for in silico analysis. Models of both ligand-free and ligandbound $h E T_{A}$ were constructed using the sequence of $h E T_{A}$ and the two crystal structures of $\mathrm{hET}_{B}$ (5GLI and 5GLH). Superimposition of the resulting two $\mathrm{hET}_{\mathrm{A}}$ models showed that the root-mean-square deviation between the two models was $2.694 \AA$ (Fig. 6a). The in silico analysis showed that the endothelin-binding site in $\mathrm{hET}_{\mathrm{A}}$ was located in the region inside the 7 transmembrane helices, as in the ET-1-bound $\mathrm{ET}_{\mathrm{B}}$ structure ${ }^{38}$, and that the conformations of two transmembrane helices (TM6 and TM7) were changed more significantly than those of the other transmembrane helices upon binding to ET-1. To analyze the AG8 binding site in $\mathrm{hET}_{\mathrm{A}}$, a structural model of AG8 was generated using Discovery Studio 2019, and the potential binding sites were listed in order of stabilization energy using the docking function of the software. The results revealed that the extracellular loop 3 (ECL3) region connected to the 6th and 7th transmembrane helices of $\mathrm{hET}_{\mathrm{A}}$ showed the most stable binding (Fig. 6b). Interestingly, this region exhibited the highest degree of conformational change upon binding to ET-1.

\section{DISCUSSION}

In this study, we overexpressed a type of GPCR with an intrinsically complex structure using a bacterial expression system and prepared a protein in the form of a nanodisc to maintain a GPCR structure similar to that of native GPCRs expressed in the cell membrane environment ${ }^{22}$. This antigen preparation strategy enabled us to isolate a human anti-GPCR antibody with high target antigen selectivity and the capability to regulate intrinsic 


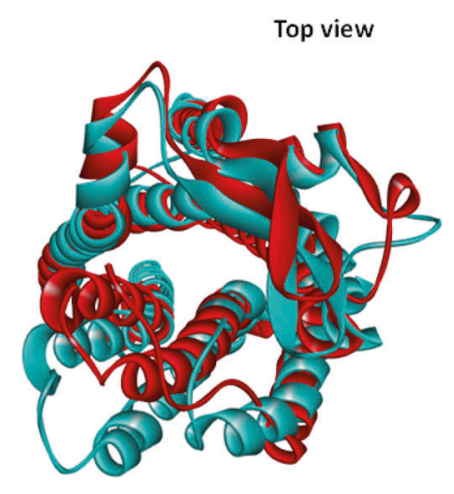

Putative AG8 binding region

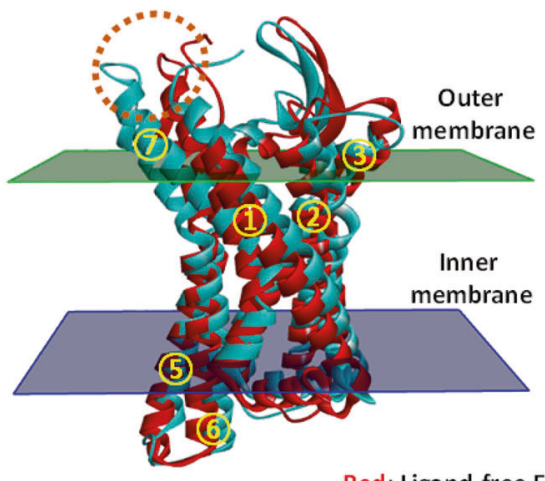

Red: Ligand-free $\mathrm{ET}_{\mathrm{A}}$

Cyan: ET-1-bound ET

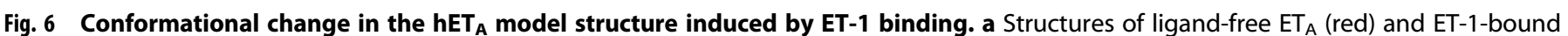
$\mathrm{ET}_{\mathrm{A}}$ (cyan). The structures are viewed from the outside of the cell (top view). $\mathbf{b}$ The structure as viewed from the side. The binding site of AG8 predicted by protein docking analysis is represented by a dotted circle. The numbers 1 through 7 in the yellow circles indicate the transmembrane domain of $\mathrm{hET}_{\mathrm{A}}$.

GPCR function. Although various GPCR antigen preparation methods, such as fusion of the GPCR extracellular region with a carrier protein, production of membrane fractions containing GPCR proteins, and synthesis of peptides of GPCR extracellular regions, have been used for GPCR antibody screens, these methods have limitations due to their strong tendency to generate GPCR conformations different from those of the native GPCR expressed in the human cell membrane, the low stability of the GPCR antigen during antibody screening steps, and the occurrence of structural modifications during chemical conjugation or genetic fusion of a part of a GPCR antigen with a carrier protein ${ }^{17}$. Our group has also fused carrier proteins such as keyhole limpet hemocyanin and ovalbumin with synthetic peptides encoding the N-terminus, extracellular loop 1 (ECL1), extracellular loop 2 (ECL2), or extracellular loop 3 (ECL3) of $\mathrm{hET}_{\mathrm{A}}$ for isolation of anti-GPCR antibodies. However, our antibody screening trial performed through animal immunization using the prepared antigen consisting of a synthetic GPCR peptide subunit fused with a carrier protein was not successful. To overcome these limitations, we prepared a GPCR antigen in nanodisc form. Nanodiscs reconstituted with a protein such as a GPCR, phospholipids, and MSPs have been used in various studies on membrane proteins ${ }^{17,39}$. Cai et al. solubilized the human glucagon-like peptide-1 receptor (GLP-1R) with detergent and successfully produced a nanodisc using MSP and phospholipids, and they confirmed binding activity with its ligand GLP-1 and with the $G_{S}$ protein ${ }^{40}$. In a similar way, the self-assembly of detergentsolubilized $\mathrm{hET}_{\mathrm{A}}$ with POPC and MSP enabled us to produce $\mathrm{hET}_{\mathrm{A}}$ nanodiscs, leading to successful isolation of an $h_{E T}$-specific human antibody.

Through a $\beta$-arrestin recruitment Tango assay ${ }^{33}$, we confirmed that the isolated antibody $A G 8$ selectively bound to $h E T_{A}$, enabling the regulation of downstream $\mathrm{hET}_{A}$ signaling. Aberrant activation and overexpression of $\mathrm{hET}_{\mathrm{A}}$ have an important effect on the survival of patients with a variety of cancers, such as breast, cervical, colorectal, ovarian, prostate, and head and neck cancers $^{14,41}$. Currently, the main antagonists targeting endothelin receptors approved for clinical trials include sitaxentan, bosentan, macitentan, and ambrisentan, all of which are small-molecule compounds. A clinical trial for sitaxentan was withdrawn, and bosentan and macitentan are dual $\mathrm{ET}_{\mathrm{A}}$ and $\mathrm{ET}_{\mathrm{B}}$ antagonists, whereas ambrisentan is the only antagonist known to selectively bind to $\mathrm{ET}_{\mathrm{A}}{ }^{42}$. Kappes et al. used ambrisentan in a preclinical murine model of metastatic breast cancer and confirmed that it inhibited cancer cell migration, invasion, and metastasis by selectively binding to $\mathrm{ET}_{\mathrm{A}}$ without interfering with the physiological vasodilator function controlled by $\mathrm{ET}_{B}{ }^{43}$. This suggests that selective binding of antagonists to a specific type of endothelin receptor is likely to be beneficial for cancer therapy. AG8 IgG, with high $\mathrm{ET}_{\mathrm{A}}$ selectivity, could be a candidate therapeutic agent for cancers in which patient survival prognosis is affected by dysfunction or overexpression of $\mathrm{ET}_{\mathrm{A}}$.

The protein sequence of $\mathrm{hET}_{\mathrm{A}}$ is $94 \%$ identical to that of its mouse homolog ${ }^{6}$. As expected, AG8 IgG showed cross-reactivity with both human and mouse $\mathrm{ET}_{\mathrm{A}}$. In the development of anticancer therapeutic antibodies, it is necessary to evaluate antitumor effects using small animal models such as mouse models prior to assessing efficacy in primates and humans. If the antibody binds to the human antigen but not to the corresponding antigen expressed in the animal model, a surrogate antibody with characteristics and binding properties similar to those of the counterpart antigen in the model animal should be produced. Alternatively, a knock-in animal model expressing the human target antigen should be used. As mentioned above, $\mathrm{ET}_{\mathrm{A}}$ has high sequence identity between humans and mice. In addition, the sequences of its ligands ET- 1 and ET-3 are identical between the two species, and another endothelin ligand, ET-2, exhibits substantial similarity (95.2\%) between humans and mice, suggesting that it is reasonable to evaluate the antitumor effects of AG8 IgG in a non-transgenic mouse xenograft model.

Representative therapeutic antibodies used for colorectal cancer treatment are bevacizumab and cetuximab. These two drugs have been administered in combination with small-molecule drugs such as irinotecan, oxaliplatin, and fluoropyrimidines in treatment regimens ${ }^{44,45}$. However, long-term treatment with bevacizumab usually increases the expression of soluble VEGF receptor 1 (sVEGFR1) and results in resistance to the drug ${ }^{46,47}$. In addition, cetuximab shows a general loss of therapeutic efficacy in patients with K-RAS mutations ${ }^{48}$. Therefore, there is an urgent unmet clinical need for the development of improved therapeutic agents for colorectal cancer. $\mathrm{ET}_{\mathrm{A}}$ is activated by both the paracrine and autocrine systems; thus, it affects cancer progression and metastasis in a variety of ways ${ }^{12,14,49-53}$. In this study, we conducted in silico analysis, and the results showed that the $\mathrm{ET}_{\mathrm{A}}$ mRNA expression level in colorectal cancer was higher than that in other cancers (breast, cervical, ovarian, prostate, and head and neck cancers) (Supplementary Fig. 1). Currently, small-molecule-based $\mathrm{ET}_{\mathrm{A}}$ antagonists with FDA approval for treating hypertension, kidney diseases, and 
heart failure have been reported to inhibit tumor progression in a variety of cancers ${ }^{54-56}$. The $\operatorname{lgG}$ antibody AG8 isolated in this study inhibited cell growth by specifically binding to $\mathrm{ET}_{\mathrm{A}}$ in colorectal cancer cells, increasing the cytosolic $\mathrm{Ca}^{2+}$ level and blocking the activation of $\mathrm{ET}_{\mathrm{A}}$ downstream signaling. In addition, the antitumor efficacy of AG8 IgG was confirmed in a colorectal cancer xenograft model. The tumor growth inhibition observed here was superior to that in a previous study based on a single administration of bevacizumab ${ }^{57}$. These results can be explained by the decreases in the levels of phosphorylated AKT, phosphorylated ERK, and cytosolic $\mathrm{Ca}^{2+}$, as well as the transcription of the colorectal cancer biomarker $\mathrm{INHBA}^{58}$, which led to inhibition of cancer cell proliferation and growth. Therefore, the results of these AG8 $\operatorname{lgG}$ analyses indicate that this antibody has a mechanism of action different from those of conventional agents for the treatment of patients with colorectal cancer that is resistant to bevacizumab and cetuximab.

To identify the specific binding epitope on $\mathrm{hET}_{\mathrm{A}}$ recognized by AG8 lgG, mass spectrometry (MS) analysis using hydrogendeuterium exchange (HDX), surface plasmon resonance analysis, and ELISA using individual $h \mathrm{hT}_{\mathrm{A}}$ extracellular loop (ECL) peptides were conducted. However, the HDX-MS analysis was not successful due to the instability of detergent-solubilized $\mathrm{hET}_{\mathrm{A}}$ during sample preparation. In addition, AG8 IgG did not bind to each individual $\mathrm{ECL}$ domain of $\mathrm{hET}_{\mathrm{A}}$, implying that each domain of the prepared $\mathrm{hET}_{\mathrm{A}}$ had a conformation different from that in the native fulllength $\mathrm{hET}_{\mathrm{A}}$ protein. However, we cannot exclude the possibility that multiple domains in addition to one $\mathrm{N}$-terminal region or $\mathrm{ECL}$ loop are involved in binding to $A G 8 \mathrm{lgG}$. To solve the tertiary structure of $\mathrm{hET}_{\mathrm{A}}$ and elucidate the interaction between $\mathrm{hET}_{\mathrm{A}}$ and AG8 IgG, we plan to replace the third intracellular loop (ICL3) with T4 lysozyme to facilitate crystallization by stabilizing the conformation of ICL3, the most flexible region in a GPCR, as reported in a previous study ${ }^{59}$.

In this study, a highly challenging GPCR antigen was prepared, and a human antibody that selectively binds to $\mathrm{hET}_{\mathrm{A}}$ was successfully isolated from a human antibody library using a phage display technique. The resulting AG8 lgG showed potent antitumor effects against colorectal cancer. To develop an antitumor therapeutic antibody with enhanced efficacy, we have engineered framework regions of the variable regions of AG8 IgG and isolated new antibodies exhibiting higher binding affinity than the parental AG8 IgG for $\mathrm{hET}_{\mathrm{A}}$. Furthermore, we will validate the antitumor efficacy and pharmacokinetics of the antibody by introducing an engineered Fc variant with a prolonged circulating half-life or enhanced effector functions. In addition, the search for additional applicable therapeutic indications is in progress, and the results will be reported in our future publications.

\section{REFERENCES}

1. Pierce, K. L., Premont, R. T. \& Lefkowitz, R. J. Seven-transmembrane receptors. Nat Rev. Mol. Cell Biol. 3, 639-650 (2002).

2. Rosenbaum, D. M., Rasmussen, S. G. F. \& Kobilka, B. K. The structure and function of G-protein-coupled receptors. Nature 459, 356-363 (2009).

3. Sriram, K. \& Insel, P. A. GPCRs as targets for approved drugs: how many targets and how many drugs? Mol. Pharmacol. 93, 251-258 (2018).

4. Hauser, A. S., Attwood, M. M., Rask-Andersen, M., Schiöth, H. B. \& Gloriam, D. E. Trends in GPCR drug discovery: new agents, targets and indications. Nat. Rev. Drug Discov. 16, 829-842 (2017).

5. Masaki, T. Possible role of endothelin in endothelial regulation of vascular tone. Annu. Rev. Pharmacol. Toxicol. 35, 235-255 (1995).

6. Davenport, A. P. et al. Endothelin. Pharmacol. Rev. 68, 357-418 (2016).

7. Takigawa, M. et al. Molecular-identification of guanine-nucleotide-binding regulatory proteins which couple to endothelin receptors. Eur. J. Biochem. 228, 102-108 (1995)

8. Shraga-Levine, Z. \& Sokolovsky, M. Functional coupling of G proteins to endothelin receptors is ligand and receptor subtype specific. Cell. Mol. Neurobiol. 20, 305-317 (2000).
9. Cramer, $\mathrm{H}$. et al. Coupling of endothelin receptors to the ERK/MAP kinase pathway-roles of palmitoylation and G alpha(q). Eur. J. Biochem. 268, 5449-5459 (2001).

10. Khimji, A.-K. \& Rockey, D. C. Endothelin-biology and disease. Cell. Signal. 22, 1615-1625 (2010).

11. Ivey, M. E., Osman, N. \& Little, P. J. Endothelin-1 signalling in vascular smooth muscle: pathways controlling cellular functions associated with atherosclerosis. Atherosclerosis 199, 237-247 (2008).

12. Bagnato, A., Loizidou, M., Pflug, B., Curwen, J. \& Growcott, J. Role of the endothelin axis and its antagonists in the treatment of cancer. Br. J. Pharmacol. 163, 220-233 (2011).

13. Enevoldsen, F. C. et al. Endothelin receptor antagonists: status quo and future perspectives for targeted therapy. J. Clin. Med. 9, 824 (2020).

14. Rosanò, L., Spinella, F. \& Bagnato, A. Endothelin 1 in cancer: biological implications and therapeutic opportunities. Nat. Rev. Cancer 13, 637-651 (2013).

15. Deng, R., Jin, F., Prabhu, S. \& Iyer, S. Monoclonal antibodies: what are the pharmacokinetic and pharmacodynamic considerations for drug development? Expert Opin. Drug Metab. Toxicol. 8, 141-160 (2012).

16. Zhao, L., Shang, E. Y. \& Sahajwalla, C. G. Application of pharmacokinetics pharmacodynamics/clinical response modeling and simulation for biologics drug development. J. Pharm. Sci. 101, 4367-4382 (2012).

17. Ju, M.-S. \& Jung, S. T. Antigen design for successful isolation of highly challenging therapeutic anti-GPCR antibodies. Int. J. Mol. Sci. 21, 8240 (2020).

18. Jo, M. \& Jung, S. T. Engineering therapeutic antibodies targeting G-proteincoupled receptors. Exp. Mol. Med. 48, e207 (2016).

19. Gibson, D. G. et al. Enzymatic assembly of DNA molecules up to several hundred kilobases. Nat. Methods 6, 343-345 (2009).

20. Lee, K. et al. Purification and characterization of recombinant human endothelin receptor type A. Protein Expr. Purif. 84, 14-18 (2012).

21. Jung, S. T. et al. Aglycosylated IgG variants expressed in bacteria that selectively bind FcyRI potentiate tumor cell killing by monocyte-dendritic cells. Proc. Natl Acad. Sci. USA 107, 604 (2010).

22. Bayburt, T. H., Grinkova, Y. V. \& Sligar, S. G. Self-assembly of discoidal phospholipid bilayer nanoparticles with membrane scaffold proteins. Nano Lett. 2, 853-856 (2002).

23. Amersdorfer, P. \& Marks, J. D. in Basic Methods in Antibody Production and Characterization, 1st edn. (eds Howard, G. C. \& Bethell, D. R.) Ch. 10, p. 106-135 (CRC Press, 2000).

24. Barbas, C. F., Kang, A. S., Lerner, R. A. \& Benkovic, S. J. Assembly of combinatorial antibody libraries on phage surfaces: the gene III site. Proc. Natl Acad. Sci. USA 88 7978-7982 (1991).

25. Kang, $\mathrm{H}$. et al. Molecular analysis of the interaction between the intracellular loops of the human serotonin receptor type $6(5-\mathrm{HT} 6)$ and the a subunit of GS protein. Biochem. Biophys. Res. Commun. 329, 684-692 (2005).

26. Longo, P. A., Kavran, J. M., Kim, M.-S. \& Leahy, D. J. in Methods in Enzymology, Vol. 529 (ed. Lorsch, J.) Ch. 18, p. 228-240 (Academic Press, 2013).

27. Lauber, M. A. et al. Rapid preparation of released N-glycans for HILIC analysis using a labeling reagent that facilitates sensitive fluorescence and ESI-MS detection. Anal. Chem. 87, 5401-5409 (2015).

28. Lim, M. S. et al. Validation of Rapi-Fluor method for glycan profiling and application to commercial antibody drugs. Talanta 198, 105-110 (2019).

29. Park, S.-J. et al. Lysophosphatidylethanolamine utilizes LPA1 and CD97 in MDAMB- 231 breast cancer cells. Cell. Signal. 25, 2147-2154 (2013).

30. Chen, R. \& Weng, Z. Docking unbound proteins using shape complementarity, desolvation, and electrostatics. Proteins 47, 281-294 (2002).

31. Tucker, J. \& Grisshammer, R. Purification of a rat neurotensin receptor expressed in Escherichia coli. Biochem. J. 317, 891-899 (1996).

32. Giudicelli, V., Chaume, D. \& Lefranc, M.-P. IMGT/GENE-DB: a comprehensive database for human and mouse immunoglobulin and $\mathrm{T}$ cell receptor genes. Nucleic Acids Res. 33, D256-D261 (2005).

33. Kroeze, W. K. et al. PRESTO-Tango as an open-source resource for interrogation of the druggable human GPCRome. Nat. Struct. Mol. Biol. 22, 362-369 (2015).

34. Stevens, T. L. et al. Arrhythmogenic cardiomyopathy: molecular insights for improved therapeutic design. J. Cardiovasc. Dev. Dis. 7, 21 (2020).

35. Hoosein, M. M. et al. Altered endothelin receptor subtypes in colorectal cancer Eur. J. Gastroenterol. Hepatol. 19, 775-782 (2007).

36. Setia, S., Nehru, B. \& Sanyal, S. N. Upregulation of MAPK/Erk and PI3K/Akt pathways in ulcerative colitis-associated colon cancer. Biomed. Pharmacother. 68, 1023-1029 (2014).

37. Zhou, G., Yang, J. \& Song, P. Correlation of ERK/MAPK signaling pathway with proliferation and apoptosis of colon cancer cells. Oncol. Lett. 17, 2266-2270 (2019).

38. Shihoya, W. et al. Activation mechanism of endothelin ETB receptor by endothelin-1. Nature 537, 363-368 (2016). 
39. Rouck, J. E., Krapf, J. E., Roy, J., Huff, H. C. \& Das, A. Recent advances in nanodisc technology for membrane protein studies (2012-2017). FEBS Lett. 591, 2057-2088 (2017).

40. Cai, Y. et al. Purification of family B G protein-coupled receptors using nanodiscs: application to human glucagon-like peptide-1 receptor. PLOS ONE 12, e0179568 (2017).

41. Galié, N., Manes, A. \& Branzi, A. The endothelin system in pulmonary arterial hypertension. Cardiovasc. Res. 61, 227-237 (2004).

42. Maguire, J. J. \& Davenport, A. P. Endothelin receptors and their antagonists. Semin. Nephrol. 35, 125-136 (2015).

43. Kappes, L. et al. Ambrisentan, an endothelin receptor type A-selective antagonist, inhibits cancer cell migration, invasion, and metastasis. Sci. Rep. 10, 15931 (2020).

44. Hurwitz, H. et al. Bevacizumab plus irinotecan, fluorouracil, and leucovorin for metastatic colorectal cancer. N. Engl. J. Med. 350, 2335-2342 (2004).

45. Cutsem, E. V. et al. Cetuximab plus irinotecan, fluorouracil, and leucovorin as firstline treatment for metastatic colorectal cancer: updated analysis of overall survival according to tumor KRAS and BRAF mutation status. J. Clin. Oncol. 29, 2011-2019 (2011).

46. Mezquita, B. et al. LoVo colon cancer cells resistant to oxaliplatin overexpress c-MET and VEGFR-1 and respond to VEGF with dephosphorylation of c-MET. Mol. Carcinog. 55, 411-419 (2016).

47. Pineda, E. et al. Dynamic soluble changes in SVEGFR1, HGF, and VEGF promote chemotherapy and bevacizumab resistance: a prospective translational study in the BECOX (GEMCAD 09-01) trial. Tumour Biol. https://doi.org/10.1177/ 1010428317705509 (2017)

48. Lièvre, A. et al. KRAS mutation status is predictive of response to cetuximab therapy in colorectal cancer. Cancer Res. 66, 3992-3995 (2006).

49. Fischer, O. M., Giordano, S., Comoglio, P. M. \& Ullrich, A. Reactive oxygen species mediate Met receptor transactivation by $G$ protein-coupled receptors and the epidermal growth factor receptor in human carcinoma cells. J. Biol. Chem. 279, 28970-28978 (2004).

50. Daub, H., Weiss, F. U., Wallasch, C. \& Ullrich, A. Role of transactivation of the EGF receptor in signalling by G-protein-coupled receptors. Nature 379, 557-560 (1996).

51. Bagnato, A., Spinella, F. \& Rosanò, L. The endothelin axis in cancer: the promise and the challenges of molecularly targeted therapy. Can. J. Physiol. Pharmacol. 86, 473-484 (2008).

52. Vacca, F., Bagnato, A., Catt, K. J. \& Tecce, R. Transactivation of the epidermal growth factor receptor in endothelin-1-induced mitogenic signaling in human ovarian carcinoma cells. Cancer Res. 60, 5310-5317 (2000).

53. Teoh, J.-P. et al. Endothelin-1/endothelin A receptor-mediated biased signaling is a new player in modulating human ovarian cancer cell tumorigenesis. Cell. Signal. 26, 2885-2895 (2014).

54. Clozel, M. Endothelin receptor antagonists: current status and perspectives. J. Cardiovasc. Pharmacol. 35, S65-S68 (2000).

55. Rosanò, L. et al. Combined targeting of endothelin A receptor and epidermal growth factor receptor in ovarian cancer shows enhanced antitumor activity. Cancer Res. 67, 6351-6359 (2007).

56. Bhargava, S. et al. Selective inhibition of endothelin receptor A as an antiangiogenic and anti-proliferative strategy for human pancreatic cancer. J. Gastrointest. Surg. 9, 703-709 (2005).

57. Mésange, P. et al. Combinations of bevacizumab and erlotinib show activity in colorectal cancer independent of RAS status. Clin. Cancer Res. 24, 2548-2558 (2018).

58. Okano, M. et al. Significance of INHBA expression in human colorectal cancer. Oncol. Rep. 30, 2903-2908 (2013).
59. Rosenbaum, D. M. et al. GPCR engineering yields high-resolution structural insights into beta2-adrenergic receptor function. Science 318, 1266-1273 (2007).

\section{ACKNOWLEDGEMENTS}

This work was supported by grants from the Bio \& Medical Technology Development Programs (2017M3A9C8060541, 2017M3A9C8060558, 2017M3A9C8060560, and 2020M3E5E2037775) and the Basic Science Research Programs (2019R1A4A1029000, 2019R1A6A3A01097279, 2018R1D1A1B07051154, and 2019R1A2C1086258) through the National Research Foundation of Korea funded by the Ministry of Science and ICT and by a National Cancer Center grant (NCC-2010250).

\section{AUTHOR CONTRIBUTIONS}

S.-G. Han, Y.G. Yu, W.-K. Lee, Y.-J. Kim, and S.T. Jung conceived the idea. M.-S. Ju, H.-M. Ahn, S.-G. Han, S. Ko, J.-H. Na, M. Jo, C.S. Lim, B.J. Ko, and W.-K. Lee conducted the experiments and performed the data analysis. M.-S. Ju. H.-M. Ahn, W.-K. Lee, Y.-J. Kim, and S.T. Jung wrote the manuscript. All authors read and approved the final manuscript.

\section{COMPETING INTERESTS}

The authors declare no competing interests.

\section{ADDITIONAL INFORMATION}

Supplementary information The online version contains supplementary material available at https://doi.org/10.1038/s12276-021-00678-9.

Correspondence and requests for materials should be addressed to Won-Kyu Lee, Youn-Jae Kim or Sang Taek Jung.

Reprints and permission information is available at http://www.nature.com/ reprints

Publisher's note Springer Nature remains neutral with regard to jurisdictional claims in published maps and institutional affiliations.

(i) Open Access This article is licensed under a Creative Commons adaptation, distribution and reproduction in any medium or format, as long as you give appropriate credit to the original author(s) and the source, provide a link to the Creative Commons license, and indicate if changes were made. The images or other third party material in this article are included in the article's Creative Commons license, unless indicated otherwise in a credit line to the material. If material is not included in the article's Creative Commons license and your intended use is not permitted by statutory regulation or exceeds the permitted use, you will need to obtain permission directly from the copyright holder. To view a copy of this license, visit http://creativecommons. org/licenses/by/4.0/.

(c) The Author(s) 2021 